\title{
Recovery of bioactive anthocyanin pigments from Ficus carica L. peel by heat, microwave, and ultrasound based extraction techniques
}

\author{
Emanueli Backes $^{\mathrm{a}, \mathrm{b}}$, Carla Pereira ${ }^{\mathrm{a}}$, Lillian Barros ${ }^{\mathrm{a}}$, M.A. Prieto ${ }^{\mathrm{a}, \mathrm{c}}$, Aziza Kamal Genena ${ }^{\mathrm{d}}$, \\ Maria Filomena Barreiro ${ }^{\mathrm{a}, \mathrm{b}}$, Isabel C.F.R. Ferreira ${ }^{\mathrm{a}, *}$ \\ ${ }^{a}$ Centro de Investigação de Montanha (CIMO), Instituto Politécnico de Bragança, Campus de Santa Apolónia, 5300-253 Bragança, Portugal \\ ${ }^{\mathrm{b}}$ Laboratory of Separation and Reaction Engineering, Laboratory of Catalysis and Materials (LSRE-LCM), Polytechnic Institute of Bragança, Campus Santa Apolónia, \\ 5300-253 Bragança, Portugal \\ ${ }^{\mathrm{c}}$ Nutrition and Bromatology Group, Faculty of Food Science and Technology, University of Vigo, Ourense Campus, E32004 Ourense, Spain. \\ d Departamento Acadêmico de Alimentos (DAALM), Universidade Tecnológica Federal do Paraná, Campus Medianeira, 85884-000 Paraná, Brazil
}

\section{A R T I C L E I N F O}

\section{Keywords:}

Ficus carica L.

Peel by-product, anthocyanin

Heat/microwave/ultrasound assisted

extraction

Response surface methodology

\begin{abstract}
A B S T R A C T
Due to its coloration, the fig (Ficus carica L.) peel, a by-product of fruit processing and/or consumption, is a potential source of anthocyanin compounds. In the present study different extraction techniques (heat, ultrasound, and microwave) were compared aiming to recover the anthocyanin pigments and optimize its extraction conditions. A response surface methodology tool with three factors and five levels for each factor was used according to a circumscribed central composite design. The variables tested for the heat and microwave extraction methods were time, temperature, and solvent proportion (ethanol/water ratio), meanwhile, for the ultrasound method, the variables tested were the ultrasonic power, time, and solvent proportion. The anthocyanin composition of the extract was determined by HPLC-DAD-ESI/MS, and the used criteria responses were: i) quantification of cyanidin 3-rutinoside $(\mathrm{C})$ in the extracted residue $(\mathrm{mg} \mathrm{C} / \mathrm{g} \mathrm{R}$ ) and in the dried peel (mg C/g P $\mathrm{dw}$ ), and the extraction yield of the obtained residue ( $\mathrm{g} \mathrm{R} / \mathrm{g} \mathrm{P} \mathrm{dw}$ ). Ultrasound extraction was the most effective method, yielding $3.82 \mathrm{mg} \mathrm{C} / \mathrm{g} \mathrm{R}$ at the optimal global extraction conditions ( $21 \mathrm{~min}, 310 \mathrm{~W}$, and $100 \%$ of ethanol). Additionally, the solid-to-liquid ratio effect was studied at the optimal conditions, using a dose-response format, in view of its plausible transference to industrial level. For the ultrasound method, an increased non-linear relationship was observed for concentrations in the range 5 to $200 \mathrm{~g} / \mathrm{L}$, being the optimal solution close to $150 \mathrm{~g} / \mathrm{L}$. In brief, the obtained results show the potential of fig peels as a source of anthocyanin pigments, with potential uses in various industrial fields, such as food, pharmaceutical, and cosmetic.
\end{abstract}

\section{Introduction}

Figs are the infructescences of a tree belonging to the family of Moraceae, called Ficus carica L., with extensive production in the Mediterranean region (Palassarou et al., 2017). When mature, the fig can acquire different colouring hues depending on its cultivar, which range from green to black-violet as a function of the anthocyanin concentration in the infructescence peel (Wang, Cui, Vainstein, Chen, \& Ma, 2017). Recent studies have shown that the fig peel contains anthocyanins at levels higher than the ones present in most of their typical natural sources (Harzallah, Bhouri, Amri, Soltana, \& Hammami, 2016; Vallejo, Marín, \& Tomás-Barberán, 2012). Figs consumption varies with the region, but for industrial purposes it is mostly used peeled (Harzallah et al., 2016), which makes the fig peel a potential by- product that can be valorised in the recovering of anthocyanin pigments.

In the last decade, researchers have proved that the regular consumption of artificial colouring agents can cause several adverse toxicological side effects on humans, such as allergic reactions, minor health disorders, and behavioural changes (Fattore et al., 2016; Montesano et al., 2008; Salem et al., 2014). Faced with this problem, and driven by consumer's needs, the food industry is decreasing the amount of used artificial colorants and, whenever possible, replacing them by more innocuous natural counterparts. These natural solutions are, not only harmless to humans when regularly consumed, but also exhibit a complementary range of important bioactivities, with beneficial health effects. These include antioxidant activity, protection against cellular oxidation, anti-inflammatory capacity, and prevention

\footnotetext{
* Corresponding author.

E-mail address: iferreira@ipb.pt (I.C.F.R. Ferreira).
} 
of chronic non-transmissible diseases, among others (Gowd, Jia, \& Chen, 2017; Rodriguez-Amaya, 2016). Therefore, the attention given by the industrial sector to these natural colorant alternatives is increasing over time, due to the urge need to find reliable solutions to replace the prevalent artificial ones. Other important features, such as the possible variation of anthocyanin chemical structure (Ongkowijoyo, Luna-Vital, \& Gonzalez de Mejia, 2018) that allow the existence of a high variety of colorations, together with their high solubility in water (Rustioni, Di Meo, Guillaume, Failla, \& Trouillas, 2013), rises the interest to screen different raw-material sources, able to reach industrial scale and contribute to make these natural solutions viable (Salem et al., 2014).

A huge array of solid-liquid extraction procedures are available to recover compounds of interest from natural matrices (Chemat et al., 2017; Montesano et al., 2008; Zhu et al., 2017). Briefly, the solid-liquid extraction consists in keeping the solid sample (usually in powder form) in direct contact with a solvent for a specific time, and by applying a certain level of energy (conventional heat, ultrasound or microwave radiation, pressure, etc.) (Fattore et al., 2016; García-Moreno et al., 2014; Zhu et al., 2016). The common solid-liquid procedures comprise the conventional methods, such as Soxhlet and heat assisted extraction (HAE, also known as maceration). These methods are easy to apply and relatively inexpensive; nevertheless several authors have pointed out some disadvantages, which are mainly associated with their application at industrial level, i.e. the use of large amounts of solvent and long extraction times (Azmir et al., 2013).

Nowadays, modern solid-liquid extraction technologies are available, such as microwave and ultrasound assisted extraction (MAE and $\mathrm{UAE}$ ), which are perceived as more sustainable, green techniques and efficient solutions for industrial application, in particular UAE (Chemat et al., 2017; Dai \& Mumper, 2010). However, conventional methods are still important at industrial level, mainly due to the lack of comparative results showing the advantages of the alternative modern techniques. For instance, the UAE can improve the recovery of bioactive components, mainly the ones that are sensitive to heat at prolonged extraction times, by keeping these variables at low levels. UAE is an effective extraction technique, in comparison to conventional methods, because the ultrasound radiation is able to disrupt cellular walls allowing a better penetration of solvents in the matrix material, thus improving mass transfer and increasing cell's content release (Bonfigli, Godoy, Reinheimer, \& Scenna, 2017; Chemat, Rombaut, Sicaire, et al., 2017). On the other hand, MAE is a process in which the applied energy accelerates the extraction (Tsatsop, Djiobie, Kenmogne, Regonne, \& Ngassoum, 2016). This method has a good performance in terms of extraction yield, solvent consumption, and extraction time, being considered a potential substitute for conventional methods (Chan, Yusoff, \& Ngoh, 2013; Meullemiestre, Breil, Abert-Vian, \& Chemat, 2016).

The recovery of natural components from vegetable matrices for implementation as food ingredients must be made under the best extraction conditions to promote its application at industrial scale and compete against the low economic cost of producing artificial dyes. The particularities of the aforementioned extraction methods, and their effectiveness, cannot be applied in a generalized way to all matrices, demanding specific optimization for each case (Jacotet-Navarro et al., 2016). Moreover, several factors may affect anthocyanin stability and, consequently, their deterioration rate, reinforcing the importance of determining the conditions that maximize the extraction yield of these compounds (Estupiñan, Schwartz, \& Garzón, 2011). In this context, the response surface methodology (RSM) arises as an important statistical method to optimize the extraction conditions and maximize responses (Sang, Sang, Ma, Hou, \& Li, 2017). The RSM consists in an assembly of mathematical and statistical techniques, helping to describe process patterns (e.g. extraction patterns) of any data set and perform predictions. The RSM procedure is essential when responses are interactively influenced by different factors, its application simplifies the system performance and optimizes the extraction conditions while maximizing the responses assessed (Bezerra et al., 2008).
Thus, the present study aims to optimize and compare anthocyanin extraction, from the peel of $F$. carica infructescences, through different extraction methodologies (HAE, UAE, and MAE). For that purpose, the joint effect of the identified relevant variables for each technique will be described through RSM. This study will allow to achieve the optimal conditions to recover anthocyanins, important pigments with a large range of colours and various industrial applications, from this natural source.

\section{Material and methods}

\subsection{Samples, standards and reagents}

The infructescences of $F$. carica were obtained in a local production at the municipality of Bragança, in Trás-os-Montes, Northeast of Portugal. They were peeled, and the peels lyophilized (FreeZone 4.5, Labconco, Kansas City, MO, USA), powdered to 20 mesh size, and stored in the freezer at $-20^{\circ} \mathrm{C}$ for subsequent extractions assays.

PA grade ethanol, hydrogen chloride, formic acid, citric acid, and HPLC grade acetonitrile were acquired from Fisher Scientific (Lisbon, Portugal). Water was treated in a Milli-Q water purification system (TGI Pure Water Systems, Greenville, SC, USA).

\subsection{Description of the extraction techniques and associated relevant variables}

The relevant variables to be considered in the optimization study by RSM were time $(t, \mathrm{~min})$, temperature $\left(T,{ }^{\circ} \mathrm{C}\right)$, and solvent proportion $(S$, $\% v / \mathrm{v}$ of ethanol in hydroalcoholic mixtures) for HAE and MAE extraction methods. For the UAE method, ultrasonic power $(P, \mathrm{~W})$, together with $t$ and $S$ were used. For all the extraction techniques, the solid-to-liquid ratio $(S / L)$ was kept constant $(50 \mathrm{~g} / \mathrm{L})$. Next, the technical requirements for each technique are briefly described.

\subsubsection{Heat-assisted extraction (HAE)}

The lyophilized powdered peel samples $(1 \mathrm{~g})$ were placed in a beaker with $20 \mathrm{~mL}$ of solvent acidified with citric acid $(\mathrm{pH}=3)$. The beaker was placed in a thermostatic water bath (Bath Shaker, OVAN, Barcelona, Spain) and the mixture was kept under continuous electromagnetic stirring (Cimarec ${ }^{\mathrm{TM}}$ Magnetic, Thermo Scientific, San Jose, CA, USA) for the required $t$. The variables and tested ranges were: $t\left(X_{1}\right.$, 5-68.8 $\mathrm{min}), T\left(X_{2}, 20-90^{\circ} \mathrm{C}\right)$, and $S\left(X_{3}, 0-100 \%\right)$.

\subsubsection{Microwave-assisted extraction (MAE)}

The MAE process was performed in a Biotage Initiator Microwave (Biotage $^{\circledR}$ Initiator + , Uppsala, Sweden) using closed vessels. The lyophilized powdered peel samples $(0.5 \mathrm{~g})$ were introduced in a closed reaction vessel with $10 \mathrm{~mL}$ of acidified solvent ( $\mathrm{pH} 3$, using citric acid). The variables of pressure and $T$ are correlated in the microwave extraction and only one can be used to maximize the responses. The effect of $T$ was used letting the other one reach the corresponding values. The microwave power was set in all cases at a constant value of $400 \mathrm{~W}$. Another important issue in the microwave extraction systems is the time interval needed to reach the selected $T$ (value that increases as the $T$ increases). For the conditions used, the time interval was always $<$ $20 \mathrm{~s}$, therefore, under this quick heating process, time interval was neglected considering only the studied extraction $t$ range. In consequence, the tested variables and ranges were $t\left(X_{1}, 5-35 \mathrm{~min}\right), T\left(X_{2}\right.$, $\left.40-115^{\circ} \mathrm{C}\right)$ and $S\left(X_{3}, 0-100 \%\right)$.

\subsubsection{Ultrasound-assisted extraction (UAE)}

The UAE was studied in a QSonica sonicators equipment (CL-334, Newtown, CT, USA) using a reaction vessel of $50 \mathrm{~mL}$ of the acidified solvent ( $\mathrm{pH} 3$, using citric acid) and $2.5 \mathrm{~g}$ of lyophilized powdered. The tested variables and ranges were at $t\left(X_{1}, 5-55 \mathrm{~min}\right), P\left(X_{2}, 100-400 \mathrm{~W}\right)$ and $S\left(X_{3}, 0-100 \%\right)$. The $T$ was monitored to ensure that the reaction 
was always below $30-35^{\circ} \mathrm{C}$.

\subsection{Anthocyanin identification and quantification}

The extraction solutions were centrifuged ( $600 \mathrm{rpm}$ for $20 \mathrm{~min}$ ) and filtered through a paper filter $n^{\circ} 4$ to remove the suspended solids. The solvent was then evaporated at $35^{\circ} \mathrm{C}$ (rotary evaporator Büchi R-210, Flawil, Switzerland) and the extracted residue gravimetrically quantified. Afterwards, it was re-dissolved in acidified water (citric acid solution with $\mathrm{pH} 3)$ and filtered through a LC filter disk $(0.22 \mu \mathrm{m})$ to a $1.5 \mathrm{~mL}$ amber vial. This solution was analysed by high-performance liquid chromatography (Dionex UltiMate 3000 UPLC, Thermo Scientific, San Jose, CA, USA), coupled to a DAD (using $520 \mathrm{~nm}$ as the preferred wavelength), and to a mass spectrometer working in positive mode using a Linear Ion Trap LTQ XL mass spectrometer (Thermo Finnigan, San Jose, CA, USA) equipped with an ESI source (Gonçalves et al., 2017). Data acquisition was performed using the Xcalibur ${ }^{\circledR}$ data system (Thermo Finnigan, San Jose, CA, USA) and quantitative analysis was performed from a 5-level calibration curve obtained from the injection of known concentrations of cyanidin 3-rutinoside $\left(\mathrm{Y}=146,924 \times-671,583 ; R^{2}=0.9989\right)$.

\subsection{Experimental design, model analysis, and statistical evaluation}

\subsubsection{RSM experimental design}

To centre correctly the experimental design preliminary trials were conducted based in one-at-the-time analysis of the studied variables for each of the selected techniques. After those preliminary analysis (data not presented), the relevant ranges were selected for each one of the studied techniques and presented in Table A1 (supplemental material). The experimental design used was the circumscribed central composite design (CCCD) with 28 response combinations using five levels for each variable.

\subsubsection{Responses applied to analyse the results}

The extraction results were expressed in three response formats $(Y)$ : $Y_{1}, \mathrm{mg}$ of cyanidin 3-rutinoside (C) obtained in the extracted dried weight residue (R; mg C/g R), which was specifically used to evaluate the purity of the target compound in the extract; $Y_{2}, \mathrm{mg}$ of $\mathrm{C}$ per $\mathrm{g}$ of peel (P) dry matter (mg C/g P dw), specifically used to analyse the extraction yield in $\mathrm{C}$; and $Y_{2} / Y_{1}$, obtained by dividing the responses $Y_{2}$ and $Y_{1}$, which provides information regarding the extraction yield in $\mathrm{R}$ ( $\mathrm{g}$ of R/g P dw).

\subsubsection{Mathematical model to describe the responses}

The RSM data was fitted by means of least-squares calculation using the following second-order polynomial equation:

$Y=b_{0}+\sum_{i=1}^{n} b_{i} X_{i}+\sum_{\substack{i=1 \\ j>i}}^{n-1} \sum_{j=2}^{n} b_{i j} X_{i} X_{j}+\sum_{i=1}^{n} b_{i i} X_{i}^{2}$

where $Y$ is the dependent variable (response) to be modelled, $X_{i}$ and $X_{j}$ define the independent variables, $b_{o}$ is the constant coefficient, $b_{i}$ is the coefficient of linear effect, $b_{i j}$ is the coefficient of interaction effect, $b_{i i}$ is the coefficient of quadratic effect, and $n$ is the number of variables. As responses, the three response formats were used: $Y_{1}(\mathrm{mg} \mathrm{C} / \mathrm{g} \mathrm{R}), Y_{2}$ (mg C/g P dw), and $Y_{2} / Y_{1}(\mathrm{~g} \mathrm{R} / \mathrm{g} \mathrm{P} \mathrm{dw}$ ).

\subsubsection{Procedure to optimize the variables to a maximum response}

To optimize the extraction conditions and maximize the responses, a simplex method was used. The predictive model obtained by RSM was employed under non-linear system with restrictions to avoid variables with unnatural physical conditions (i.e., $t \geq 0$ ) and a maximization was obtained (Vieira et al., 2017).

\subsection{Dose-response description of the solid-to-liquid ratio effect}

The analysis of the solid-to-liquid ratio $\left(S / L\right.$ or $X_{4}$, expressed in $\left.\mathrm{g} / \mathrm{L}\right)$ was performed by a dose-response at the optimal conditions of the variables found by the RSM $\left(X_{1}, X_{2}\right.$, and $\left.X_{3}\right)$. The aim was to achieve the $S / L$ conditions that leads to a more productive processes for industrial applications. To depict the response effect as function of the $S / L$, the Weibull (W) equation (Prieto, Curran, Gowen, \& Vázquez, 2015) for increasing $(\uparrow)$ and decreasing $(\downarrow)$ responses was used (with some parametric modifications to fit the searched purposes):

$$
\begin{aligned}
\uparrow W\left(X_{4}\right) & \left.=K \exp \left[\ln (1-n / 100)\left(\frac{X_{4}}{m_{n}}\right)^{a}\right] \text { or }\right\rfloor W\left(X_{4}\right) \\
& =K-K \exp \left[\ln (1-n / 100)\left(\frac{X_{4}}{m_{n}}\right)^{a}\right]
\end{aligned}
$$

where $K$ is the maximum extraction value (i.e., if $Y_{2}$ the units would be in $\mathrm{mg} \mathrm{C} / \mathrm{g} \mathrm{P} \mathrm{dw}$ ), $a$ is a shape parameter related to the maximum slope of the response, $n$ is any desired level between 0 and $100 \%$ of the response $\left(Y_{1}, Y_{2}\right.$, and $\left.Y_{2} / Y_{1}\right)$ that would be achieved and $m_{n}$ would be the $S / L$ value $\left(X_{4}\right)$ for the selected $n$ response level $\left(m_{10}, m_{25}, m_{75}, m_{95}\right.$, etc.). For example, if the $n$ value is selected as $99 \%$, the $m_{n}$ parameter will display de $S / L$ needed to achieve the $99 \%$ of the assessed response $\left(m_{99 \%}\right)$. When the response shows increasing patterns $(\uparrow)$, the Weibull equation that is used to describe the response will present a $m_{n}$ parameter of $n=99 \%$. When the response shows decreasing patterns $(\downarrow)$, a $m_{n}$ parameter with $n=50 \%$ will be used. These different levels of the responses as a function of their increasing or decreasing patterns are logical relations of the intrinsic solutions for industrial purposes. When the response increases, it is logical to know the maximum $S / L$ leading to a $99 \%$ level of the assessed response $\left(m_{99 \%}\right)$. However, when the response decreases, the value of $m_{99 \%}$ will tend to zero, therefore, it seems to be logical to search for values not decreasing our response more than the half of the maximum (such as $m_{50 \%}$ ). If other $m_{n}$ is required, Eq. (2) can be modified to produce any other desirable result. However, the selected values for the parameters $K$ and $m_{n}$ will provide key information related to the pattern of the response to assess the effect of the $S / L$.

\subsection{Numerical methods, statistical analysis, and graphical illustrations}

Fitting procedures, coefficient estimates, and statistical calculations were achieved as previously described by other authors (Prieto \& Vázquez, 2014). In brief, a) the parameter's determination was accomplished using the quasi-Newton algorithm (least-square) by running the integrated macro 'Solver' in Microsoft Excel by minimizing the differences between observed and predicted values; b) the coefficient significance was evaluated using the 'SolverAid' macro to determine their intervals $(\alpha=0.05)$; and $\mathrm{c}$ ) the model consistency was checked by means of several statistical criteria: ci) the Fisher $F$-test $(\alpha=0.05)$ was used to assess the adequacy of the models to describe the observed data; cii) the 'SolverStat' macro was used to assess parameter and model prediction uncertainties (Murado \& Prieto, 2013); and ciii) the $R^{2}$ value was interpreted as the amount of variability of the dependent variable that is explained by the model.

\section{Results and discussion}

\subsection{Optimization of the RSM analysis using the 3 relevant variables for each extraction technique}

3.1.1. Preliminary experiments to select the relevant variables and ranges for designing an appropriate RSM

The extraction of target compounds from natural matrices requires specific considerations due to the intrinsic features and stability of these compounds, and such analysis cannot be extrapolated from similar sources. An in-depth extraction study is required to determine the best 
solid-to-liquid extraction method, and operating conditions, for the extraction of target compounds from a certain natural matrix, otherwise, results may lead to erroneous conclusions.

The anthocyanin profile of fig peel extracts was obtained by HPLCDAD-ESI/MS is presented in Fig. A1. Among another minor component, cyanidin 3-rutinoside $\left([\mathrm{M}-\mathrm{H}]^{-}\right.$at $m / z$ 595), which is the molecule responsible for the colorant capacity, was identified. To maximize the extraction of cyanidin 3-rutinoside (C), it is indispensable to identify the effects of variables on responses. A minimum time, energy, and solvent consumption, in order to achieve the most cost-effective and profitable extraction system, is intended (Dai \& Mumper, 2010). The RSM design allows optimizing all the variables simultaneously considering interactive effects and predicting the most efficient conditions. Based on the tested experimental range and by using second order polynomial models with interactions, the RSM technique provides for the selected responses used as criteria, a truthful description and the optimal conditions that maximize/minimize them (Bezerra et al., 2008; Ferreira et al., 2007; Kalil \& Maugeri, 2000). When applying RSM, the initial difficulties are to select the important involved factors and their relevant experimental range. To overcome those issues, preliminary laboratory tests using the one-factor-at-the-time method (keeping the other variables constant) were performed. Once these preliminary analyses were completed (data not shown), the factors selected for the RSM application were $t, T$, and $S$ for the HAE and MAE systems, and $t, P$, and $S$ for the UAE system. Similar findings were reported by other authors when performing optimization studies with other natural matrices (Albuquerque et al., 2016; Caleja et al., 2017). A detailed description for all tested values for each technique can be found in Table A1 (supplemental material section). Concerning the type of employed solvent, and since anthocyanins are polar pigments, they were extracted with hydroalcoholic solutions (ethanol/water mixtures). In all cases, ethanol content was tested in the range 0 to $100 \%$, and confirmed as impacting significantly the achieved anthocyanin extraction yield. In order to maintain anthocyanin stability, citric acid was added to the extraction solvent in order to obtain a pH value around 3. For the RSM study, the $S / L$ variable was kept at $50 \mathrm{~g} / \mathrm{L}$ (constant value).

In conclusion, the efficiency of the HAE, UAE, and MAE processes for extracting cyanidin 3-rutinoside from fig peel was performed by applying a RSM using three variables in a CCCD (five values for each factor). The coded values, and respective natural values, are presented in Table A1. Once the optimal conditions $(t, T$, and $S$ for HAE and MAE, and $t, P$, and $S$ for UAE) were optimized, the study was further advanced towards the study of the $S / L$ effects.

Fig. A2 (presented in the supplemental material section) shows a diagram summary of the work achieved and the steps carried out to optimize the conditions that maximize the extraction of the detected anthocyanin compound in the fig peel (cyanidin 3-rutinoside).

\subsubsection{Developed mathematical models after the RSM application}

Table 1 shows the results of the responses considered. The Eq. (1) was employed to fit the responses in Table 1 using nonlinear leastsquares estimations. The parametric values with higher confidence interval values than the parameter value, were considered as non-significant (ns), and were not used for the model development (Ranic et al., 2014). Table 2 part A shows the significant parametric values of Eq. (1) obtained and the confidence interval values $(\alpha=0.05)$. The $n s$ parameters of RSM approaches (Table 2A) do not improve the reached solutions, but rise the uncertainties of all significant coefficients, and in addition, the $n s$ parameters will alter the solutions in untested conditions. Based on the results of Table 2A, the final significant models for each assessed extraction technique are described below:

For the response format $Y_{1}(\mathrm{mg} \mathrm{C} / \mathrm{g} \mathrm{R})$ :

for HAE:
forHAE: $Y_{H A E}^{Y_{1}}=3.71-0.22 t+0.22 T+1.30 S-1.17 t^{2}-0.05 T^{2}$

$$
+0.17 t T-0.08 T S
$$

for UAE

$Y_{U A E}^{Y_{1}}=5.51+0.21 t+0.61 P+2.05 S-0.63 P^{2}+0.27 S^{2}+0.19 t S$

for MAE

$Y_{M A E}^{Y_{1}}=6.17-0.35 t-0.52 T+1.58 S-0.49 T^{2}-0.35 t T-0.31 t T$ $-0.36 T S$

For the response format $Y_{2}(\mathrm{mg} \mathrm{C} / \mathrm{g} \mathrm{P} \mathrm{dw})$ :

for HAE

$Y_{H A E}^{Y_{2}}=14.74-0.86 t-1.36 T+3.89 S-0.98 T^{2}-0.91 S^{2}-0.74 t T$

$-0.9 T S$

for UAE

$Y_{U A E}^{Y_{2}}=4.24+0.11 t+0.42 P+0.88 S-0.067 t^{2}-0.39 P^{2}-0.26 S^{2}$

$$
+0.09 t S-0.07 P S
$$

for MAE

$Y_{M A E}^{Y_{2}}=4.46-0.28 t-0.36 T+1.09 S-0.39 T^{2}-0.23 S^{2}-0.24 t T$ $-0.24 T S$

For the response format $Y_{2} / Y_{1}(\mathrm{~g} \mathrm{R} / \mathrm{g} \mathrm{P} \mathrm{dw})$ :

for HAE

$Y_{H A E}^{Y_{2} / Y_{1}}=0.69+0.02 t+0.02 T-0.01 t T+0.01 t S+0.01 T S$

for UAE

$Y_{U A E}^{Y_{2} / Y_{1}}=0.78+0.01 t+0.01 P-0.09 S-0.01 t^{2}-0.05 S^{2}$

for MAE

$Y_{M A E}^{Y_{2} / Y_{1}}=0.72-0.01 S-0.01 T^{2}-0.01 S^{2}-0.01 t S$

The variables of models (3) to (11) derived from Eq. (1) where $X_{1}(t$, $\min ), X_{2}\left(T,{ }^{\circ} \mathrm{C}\right.$ or $\left.P, \mathrm{~W}\right)$, and $X_{3}(S, \%)$, whereas $Y$ is the response, subindices indicate the applied technique, and the super-indices the three used response criteria ( $Y_{1}$ in $\mathrm{mg} \mathrm{C} / \mathrm{g} \mathrm{R}, Y_{2}$ in $\mathrm{mg} \mathrm{C} / \mathrm{g} \mathrm{P} \mathrm{dw}$, and $Y_{2} / Y_{1}$ in $\mathrm{g} \mathrm{R} / \mathrm{g} \mathrm{P} \mathrm{dw}$ ). Therefore, eqs. (3) to (11) translate the response patterns, showing a relatively high complexity (higher than 6 parameters) of the possible sceneries for $Y_{1}$ and $Y_{2}$ value formats and relatively simple solutions for the $Y_{2} / Y_{1}$ response value format (lesser than 6 parameters).

Because the experimental plan is based on coded values of the variables, the obtained model coefficients are empirical and cannot be associated with physical or chemical significance. However, their numerical values can be used for direct comparisons. In fact, the higher is the absolute value of the coefficient, the more important will be the weight of the corresponding variable. Correspondingly, when a factor has a positive effect, the response increases as the values of the involved variable rises, and when the factor has a negative effect, the response decreases.

Eqs. (3) to (11) provide a comprehensive summary of the effects produced by each of the variables defined for the assessed extraction techniques. Several statistical tests were employed to evaluate the ability of the obtained Eqs. (3) to (11) and the results are presented in Table 2B. Overall, the statistical tests are conclusive providing the same findings: Eqs. (3) to (11) are efficient in the subsequent prediction stages. In this regard, and comparatively to the most common statistical criteria presented in Table $2 \mathrm{~B}$, the coefficients $R^{2}$ and $R_{\text {adj }}^{2}$, almost in all cases, displayed results higher than 0.9, which indicates a good agreement between the experimental and predicted values. This implies that the variation of the experimental results can be explained by the independent processing variables by using the specific parametric values presented in Table 2A, which validates the models of Eqs. (3) to 
Table 1

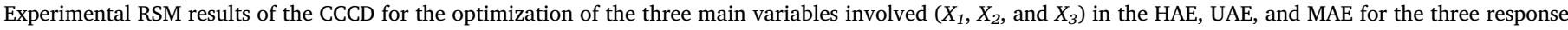

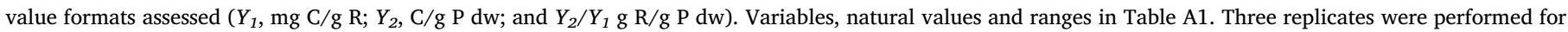
each condition for each technique.

\begin{tabular}{|c|c|c|c|c|c|c|c|c|c|c|c|}
\hline \multicolumn{3}{|c|}{ Variable coded values } & \multicolumn{3}{|c|}{ Experimental responses } & \multicolumn{3}{|l|}{ UAE } & \multicolumn{3}{|l|}{ MAE } \\
\hline & & & \multicolumn{3}{|l|}{ HAE } & & & & & & \\
\hline$X_{1}$ & $X_{2}$ & $X_{3}$ & $Y_{1}$ & $Y_{2}$ & $Y_{2} / Y_{1}$ & $Y_{1}$ & $Y_{2}$ & $Y_{2} / Y_{1}$ & $Y_{1}$ & $Y_{2}$ & $Y_{2} / Y_{1}$ \\
\hline-1 & -1 & -1 & 1.031 & 0.709 & 0.688 & 1.783 & 1.304 & 0.731 & 2.997 & 2.376 & 0.793 \\
\hline-1 & -1 & 1 & 6.731 & 5.137 & 0.763 & 8.272 & 5.820 & 0.704 & 7.993 & 5.623 & 0.704 \\
\hline-1 & 1 & -1 & 1.753 & 1.072 & 0.612 & 3.537 & 2.591 & 0.732 & 3.738 & 2.908 & 0.778 \\
\hline-1 & 1 & 1 & 5.944 & 4.660 & 0.784 & 6.932 & 5.002 & 0.722 & 7.602 & 5.413 & 0.712 \\
\hline 1 & -1 & -1 & 1.016 & 0.682 & 0.671 & 2.265 & 1.635 & 0.722 & 3.213 & 2.384 & 0.742 \\
\hline 1 & -1 & 1 & 5.042 & 3.792 & 0.752 & 9.915 & 7.333 & 0.740 & 7.702 & 5.357 & 0.695 \\
\hline 1 & 1 & -1 & 2.622 & 1.869 & 0.713 & 2.091 & 1.606 & 0.768 & 3.159 & 2.477 & 0.784 \\
\hline 1 & 1 & 1 & 6.163 & 4.738 & 0.769 & 8.585 & 6.112 & 0.712 & 6.267 & 4.393 & 0.701 \\
\hline-1.68 & 0 & 0 & 3.702 & 1.782 & 0.661 & 4.865 & 3.604 & 0.741 & 5.994 & 4.501 & 0.751 \\
\hline 1.68 & 0 & 0 & 2.326 & 1.570 & 0.675 & 5.574 & 3.880 & 0.696 & 6.324 & 4.522 & 0.715 \\
\hline 0 & -1.68 & 0 & 3.489 & 2.325 & 0.666 & 2.647 & 1.885 & 0.712 & 6.351 & 4.576 & 0.720 \\
\hline 0 & 1.68 & 0 & 3.206 & 2.133 & 0.665 & 5.096 & 3.767 & 0.739 & 2.498 & 1.706 & 0.683 \\
\hline 0 & 0 & -1.68 & 0.999 & 0.688 & 0.689 & 2.299 & 1.749 & 0.760 & 2.531 & 1.982 & 0.761 \\
\hline 0 & 0 & 1.68 & 6.051 & 4.345 & 0.718 & 10.307 & 4.576 & 0.444 & 7.209 & 5.324 & 0.739 \\
\hline-1.68 & -1.68 & -1.68 & 1.098 & 0.765 & 0.696 & 0.576 & 0.406 & 0.705 & 1.449 & 0.948 & 0.655 \\
\hline-1.68 & -1.68 & 1.68 & 6.777 & 2.405 & 0.355 & 4.875 & 1.936 & 0.397 & 7.834 & 5.546 & 0.708 \\
\hline-1.68 & 1.68 & -1.68 & 2.665 & 1.864 & 0.699 & 3.140 & 2.417 & 0.770 & 2.775 & 1.930 & 0.696 \\
\hline-1.68 & 1.68 & 1.68 & 4.975 & 3.716 & 0.747 & 7.648 & 3.273 & 0.428 & 6.757 & 5.142 & 0.761 \\
\hline 1.68 & -1.68 & -1.68 & 0.773 & 0.518 & 0.670 & 0.421 & 0.348 & 0.827 & 1.066 & 0.841 & 0.788 \\
\hline 1.68 & -1.68 & 1.68 & 3.553 & 2.636 & 0.742 & 6.213 & 2.443 & 0.393 & 8.641 & 5.958 & 0.689 \\
\hline 1.68 & 1.68 & -1.68 & 2.128 & 1.551 & 0.729 & 2.623 & 2.302 & 0.878 & 0.488 & 0.360 & 0.739 \\
\hline 1.68 & 1.68 & 1.68 & 5.747 & 4.234 & 0.737 & 9.145 & 4.324 & 0.473 & 1.973 & 1.505 & 0.762 \\
\hline 0 & 0 & 0 & 2.428 & 1.639 & 0.675 & 4.734 & 3.496 & 0.738 & 6.720 & 4.882 & 0.726 \\
\hline 0 & 0 & 0 & 2.558 & 1.669 & 0.652 & 5.751 & 4.654 & 0.809 & 6.251 & 4.591 & 0.734 \\
\hline 0 & 0 & 0 & 2.510 & 1.657 & 0.660 & 5.256 & 4.165 & 0.792 & 6.065 & 4.212 & 0.695 \\
\hline 0 & 0 & 0 & 3.049 & 2.090 & 0.686 & 5.340 & 4.449 & 0.833 & 6.063 & 4.244 & 0.700 \\
\hline 0 & 0 & 0 & 2.558 & 1.733 & 0.678 & 5.177 & 4.020 & 0.776 & 5.863 & 4.233 & 0.722 \\
\hline 0 & 0 & 0 & 2.555 & 1.725 & 0.675 & 5.907 & 4.652 & 0.788 & 6.747 & 2.376 & 0.684 \\
\hline
\end{tabular}

(11) and allows to move to the interpretation of the independent variable effects and the determination of the optimal conditions that maximize the responses.

\subsubsection{Effect of the independent variables on the target responses and optimal extraction conditions}

The second-order polynomial model of Eq. (1), which has proved its suitability in the previous section, describe two types of effects (linear and non-linear) for each variable and one interactive effect between two pairs of variables. The patterns of the extraction can be explained by means of the parametric values of the second-order polynomial models shown in Table 2A or Eqs. (3) to (11), as described above, or can be illustrated by graphical representations. In this regard, Fig. 1, Fig. A3, and Fig. A4 (supplementary material) show the extraction results for the three response criteria formats for each assessed technique, respectively. The figures are divided in three columns, each one showing the response results $\left(Y_{1}, Y_{2}\right.$, and $\left.Y_{2} / Y_{1}\right)$ for each of the tested techniques. Additionally, each column is divided into two sections (A and B):

- Section A shows the three-dimensional surface figures for the three possible variable combinations produced by the developed Eqs. (3) to (11). The studied responses (dependent variables) are visualized as a function of the corresponding independent variables by drawing the responses generated by the models. The plots were built by fluctuating two variables within the experimental range and holding the excluded variable constant at the centre of their experimental domain (Table A1). It can be observed that the obtained amount of cyanidin 3-rutinoside is highly dependent on the $S$ variable, for all the tested extraction methods. For the UAE, the effect of the $P$ variable is also considerable, although not so significant as the effect of $S$. The analysis of the 3D graphs presented in Fig. 1 shows the low influence of $t$ and $T$ on the response of the HAE and MAE methods.
The quadratic effect of the variables observed in HAE was found important, whereas for UAE and MAE the detected relevant effects were the interactive ones.

- Section B illustrates the capability to predict the obtained results and the residual distribution as a function of each one of the considered variables. The statistical information is displayed using two basic graphical criteria, depicting the capacity to predict the obtained results. As previously described in Table 2B, in all cases, the coefficient $R^{2}$ displays values higher than 0.9 and the graphical distribution shows the experimental data versus the ones predicted by the model with a linear arrangement, proving the consistency of the RSM models. In addition, the distribution of the residuals as function of each variable are graphically represented and no grouped data or autocorrelations were observed.

\subsubsection{Optimal conditions that favours the extraction of anthocyanins and its experimental verification}

Once models are statistically and graphically validated, the optimization of the variable conditions to maximize the response values (or minimize, depending on the requirements) was performed by numerical analysis using the simplex procedure. Table $3 \mathrm{~A}$ shows the variable conditions that optimize the three assessed responses $\left(Y_{1}, Y_{2}\right.$, and $Y_{2} /$ $Y_{1}$ ), individually, while Table 3B presents the results of an overall optimization of these responses.

Once the numerical values of the optimal conditions and the maximum responses are achieved, the tendencies of each response were represented in Fig. 2. The graphical illustration allows the visual selection of the most favourable conditions, taking into account simultaneously all responses when the excluded variable is positioned at the individual optimal values of the others (Table 3A). Fig. 2 shows the isolines projections for the combination of the three main involved variables $\left(\times_{1}, x_{2}\right.$, and $\left.x_{3}\right)$ in the HAE, MAE, and UAE, for the three 


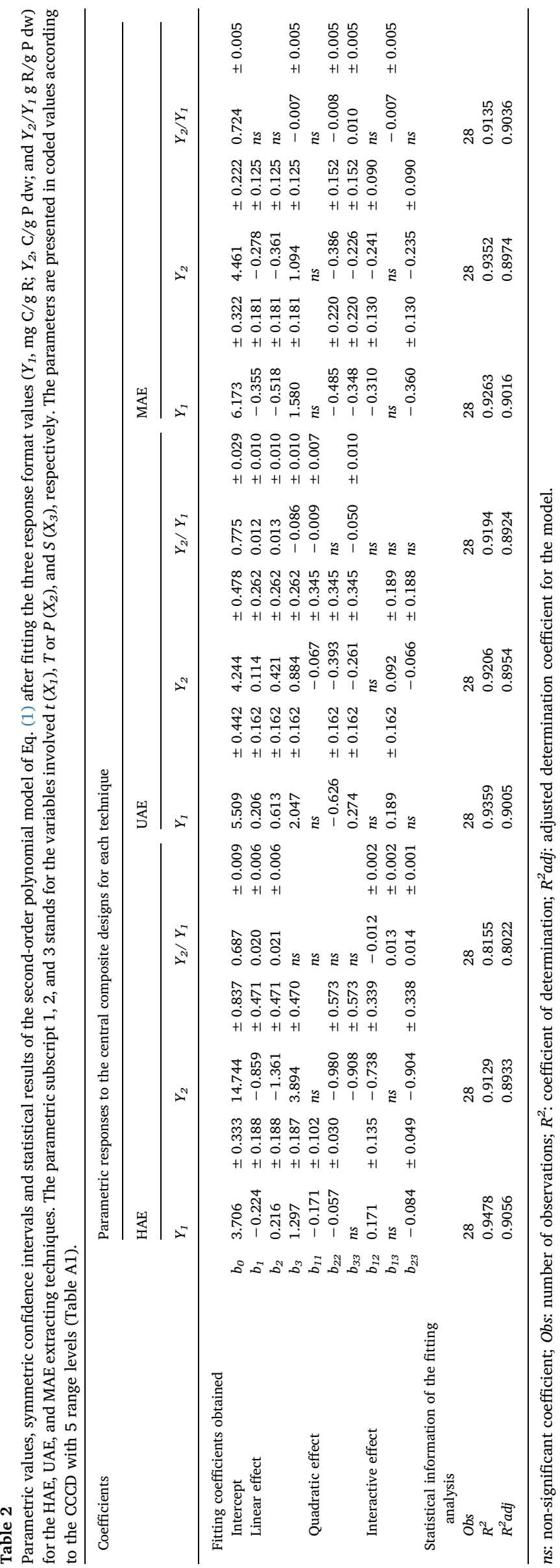



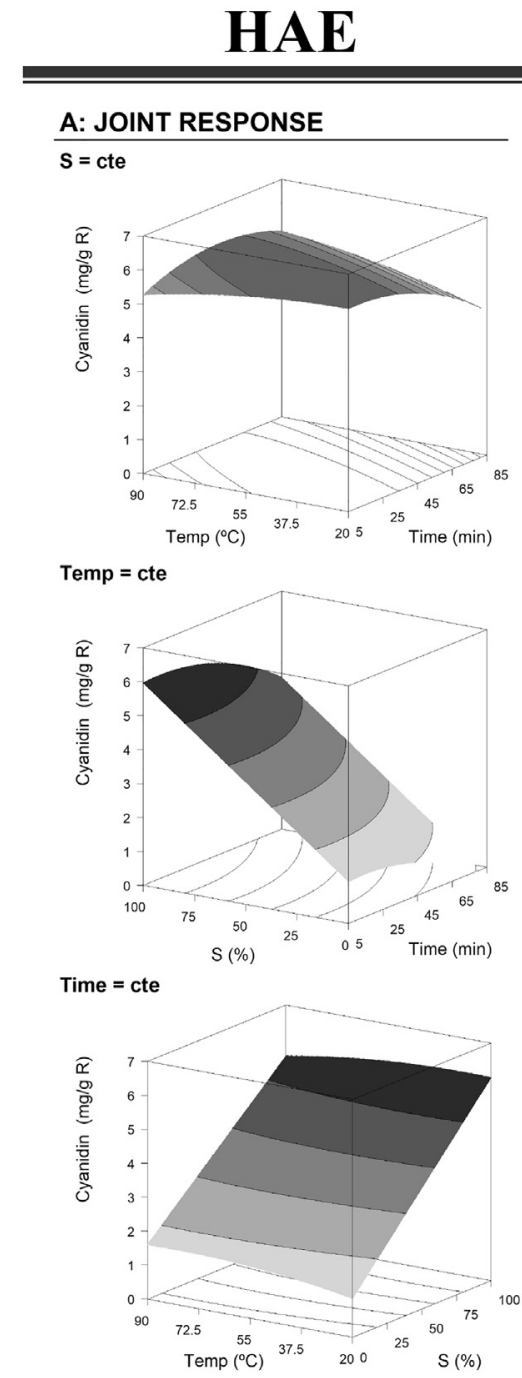

B: STATISTICAL DISTRIBUTION

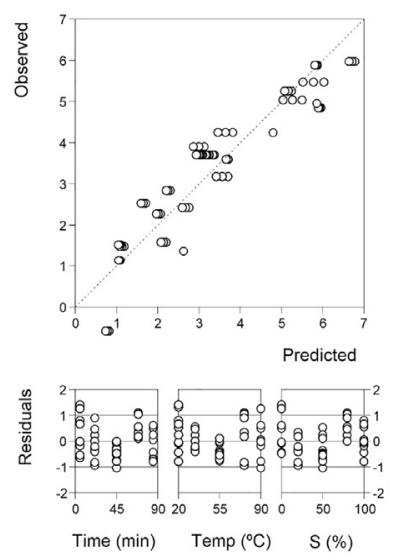

UAE

A: JOINT RESPONSE

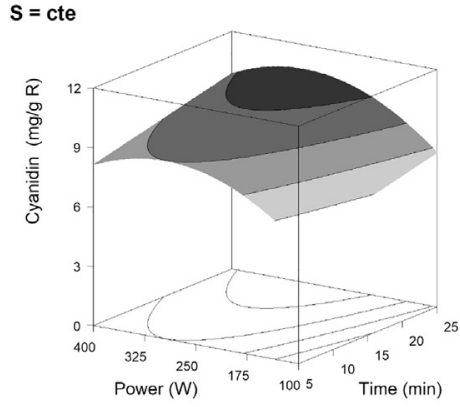

Power $=$ cte

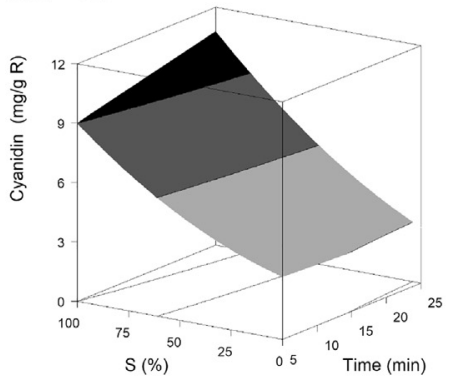

Time $=$ cte

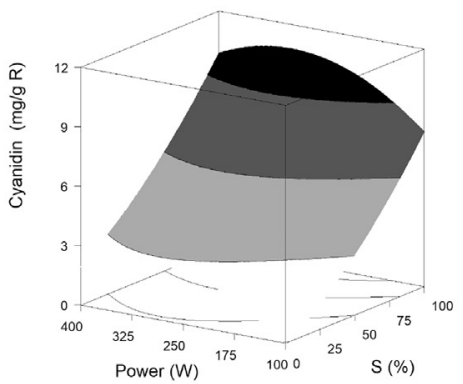

B: STATISTICAL DISTRIBUTION
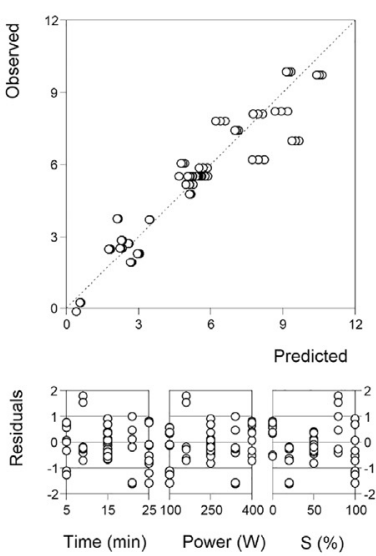

MAE

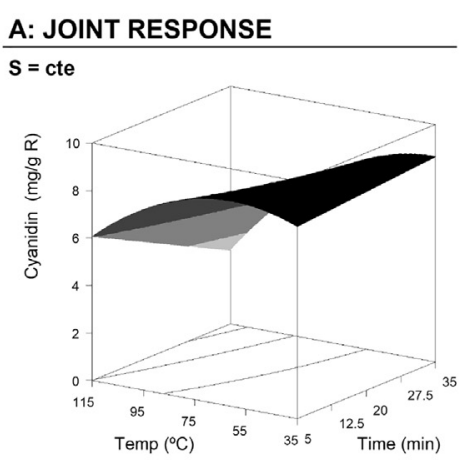

Temp $=$ cte

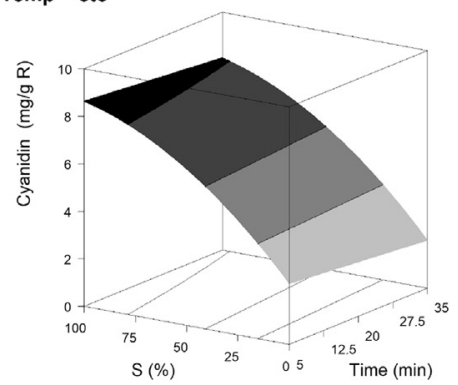

Time $=$ cte

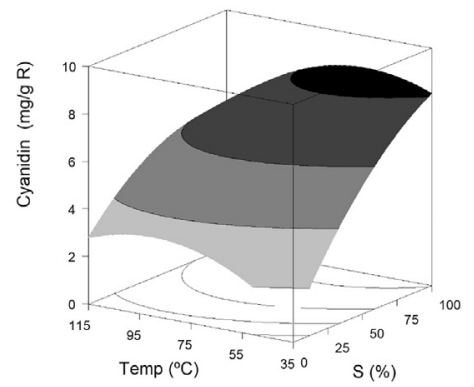

B: STATISTICAL DISTRIBUTION
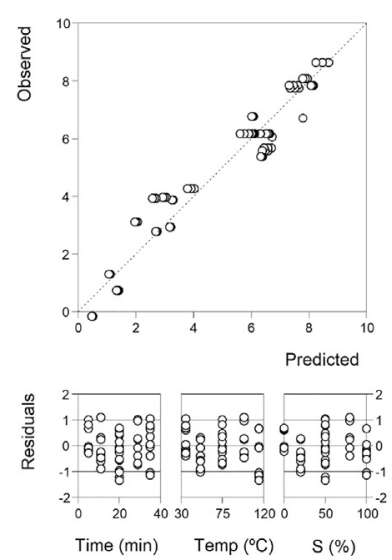

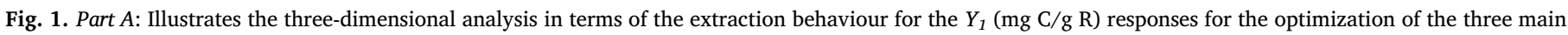

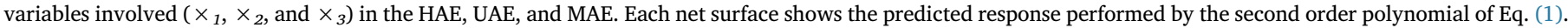

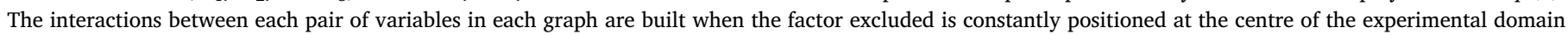

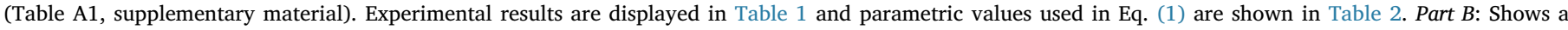

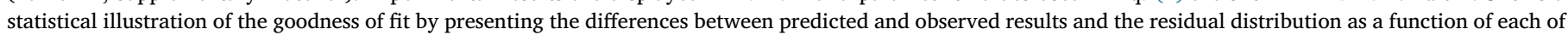
the variables.

response value formats ( $Y_{1}, \mathrm{mg} \mathrm{C} / \mathrm{g} \mathrm{R} ; Y_{2}, \mathrm{mg} \mathrm{C} / \mathrm{g} \mathrm{P} \mathrm{dw}$; and $Y_{2} / Y_{1} \mathrm{~g} \mathrm{R} /$ $\mathrm{g} P \mathrm{dw})$. The isolines presented in the $\mathrm{XY}$ plane are derived from the three-dimensional responses obtained from the second-order polynomial equation of Eqs. (3) to (11). Their analysis is important for decision making when choosing the best conditions to perform the extractions. 
Table 3

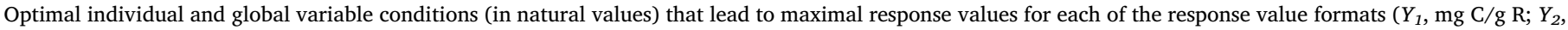
$\mathrm{C} / \mathrm{g} \mathrm{P} \mathrm{dw}$; and $Y_{2} / Y_{1} \mathrm{~g} \mathrm{R} / \mathrm{g} \mathrm{P}$ dw) for each extracting technique assessed (HAE, UAE, and MAE).

\begin{tabular}{|c|c|c|c|c|c|c|}
\hline \multirow[t]{2}{*}{ Criteria } & & \multicolumn{3}{|c|}{ Optimal Variable Conditions } & \multicolumn{2}{|c|}{ Optimum Response } \\
\hline & & $X_{1}: t(\min )$ & $X_{2}: T\left({ }^{\circ} \mathrm{C}\right)$ or $P(\mathrm{~W})$ & $X_{3}: S(\%)$ & & \\
\hline \multicolumn{7}{|c|}{ A) Individual optimal variable conditions: } \\
\hline \multirow[t]{3}{*}{ HAE } & $Y_{1}$ & $14.24 \pm 0.16$ & $28.26 \pm 2.83$ & $100.00 \pm 2.12$ & $5.99 \pm 0.60$ & $\mathrm{mg} \mathrm{C} / \mathrm{g} \mathrm{R}$ \\
\hline & $Y_{2}$ & $49.25 \pm 2.48$ & $90.00 \pm 8.10$ & $100.00 \pm 2.83$ & $4.50 \pm 0.27$ & $\mathrm{mg} \mathrm{C} / \mathrm{g} \mathrm{P} \mathrm{dw}$ \\
\hline & $Y_{2} / Y_{1}$ & $85.00 \pm 8.50$ & $90.00 \pm 3.60$ & $100.00 \pm 1.43$ & $0.80 \pm 0.08$ & $\mathrm{~g} \mathrm{R} / \mathrm{g} \mathrm{P}$ dw \\
\hline \multirow[t]{3}{*}{ UAE } & $Y_{1}$ & $21.00 \pm 1.89$ & $309.53 \pm 3.10$ & $100.00 \pm 1.45$ & $9.56 \pm 0.48$ & $\mathrm{mg} \mathrm{C} / \mathrm{g} \mathrm{R}$ \\
\hline & $Y_{2}$ & $25.00 \pm 1.75$ & $285.07 \pm 19.95$ & $100.00 \pm 2.04$ & $5.32 \pm 0.37$ & $\mathrm{mg} \mathrm{C} / \mathrm{g} \mathrm{P} \mathrm{dw}$ \\
\hline & $Y_{2} / Y_{1}$ & $23.61 \pm 1.18$ & $394.76 \pm 3.95$ & $19.96 \pm 1.42$ & $0.84 \pm 0.08$ & $\mathrm{~g} \mathrm{R} / \mathrm{g} \mathrm{P} \mathrm{dw}$ \\
\hline \multirow[t]{3}{*}{ MAE } & $Y_{1}$ & $5.00 \pm 0.10$ & $60.27 \pm 4.22$ & $100.00 \pm 3.19$ & $8.63 \pm 0.69$ & $\mathrm{mg} \mathrm{C} / \mathrm{g} \mathrm{R}$ \\
\hline & $Y_{2}$ & $5.00 \pm 0.05$ & $64.21 \pm 1.28$ & $100.00 \pm 2.48$ & $6.21 \pm 0.56$ & $\mathrm{mg} \mathrm{C} / \mathrm{g} \mathrm{P} \mathrm{dw}$ \\
\hline & $Y_{2} / Y_{1}$ & $35.00 \pm 1.05$ & $75.00 \pm 6.75$ & $0.00 \pm 1.63$ & $0.78 \pm 0.02$ & $\mathrm{~g} \mathrm{R} / \mathrm{g} \mathrm{P}$ dw \\
\hline \multicolumn{7}{|c|}{ B) Global optimal variable conditions: } \\
\hline \multirow[t]{3}{*}{ HAE } & $Y_{1}$ & $13.74 \pm 1.91$ & $35.64 \pm 7.98$ & $100.00 \pm 1.36$ & $5.78 \pm 0.12$ & $\mathrm{mg} \mathrm{C} / \mathrm{g} \mathrm{R}$ \\
\hline & $Y_{2}$ & & & & $4.03 \pm 0.22$ & $\mathrm{mg} \mathrm{C} / \mathrm{g} \mathrm{P} \mathrm{dw}$ \\
\hline & $Y_{2} / Y_{1}$ & & & & $0.56 \pm 0.02$ & $\mathrm{~g} \mathrm{R} / \mathrm{g} \mathrm{P} \mathrm{dw}$ \\
\hline \multirow[t]{3}{*}{ UAE } & $Y_{1}$ & $21.34 \pm 0.55$ & $310.58 \pm 25.89$ & $100.00 \pm 1.23$ & $9.01 \pm 0.76$ & $\mathrm{mg} \mathrm{C} / \mathrm{g} \mathrm{R}$ \\
\hline & $Y_{2}$ & & & & $4.32 \pm 0.14$ & $\mathrm{mg} \mathrm{C} / \mathrm{g} \mathrm{P} \mathrm{dw}$ \\
\hline & $Y_{2} / Y_{1}$ & & & & $0.51 \pm 0.21$ & $\mathrm{~g} \mathrm{R} / \mathrm{g} \mathrm{P} \mathrm{dw}$ \\
\hline \multirow[t]{3}{*}{ MAE } & $Y_{1}$ & $5.00 \pm 0.30$ & $62.41 \pm 0.57$ & $100.00 \pm 3.73$ & $7.43 \pm 0.78$ & $\mathrm{mg} \mathrm{C} / \mathrm{g} \mathrm{R}$ \\
\hline & $Y_{2}$ & & & & $4.11 \pm 0.37$ & $\mathrm{mg} \mathrm{C} / \mathrm{g} \mathrm{P} \mathrm{dw}$ \\
\hline & $Y_{2} / Y_{1}$ & & & & $0.76 \pm 0.04$ & g R/g P dw \\
\hline
\end{tabular}

Finally, Fig. 3A shows a 2D graphical representation, in which the lines show the response predicted by the models described in Eqs. (3) to (11), when the other studied variables are fixed at their optimal values. The response axes $(Y)$ were maintained on the same scale to facilitate the comparison among the used extraction techniques. The dots $(\odot)$ presented alongside the line highlight the location of the optimal value (Table 3A).

When combining the information produced by the three response criteria $\left(Y_{1}, Y_{2}\right.$, and $\left.Y_{2} / Y_{1}\right)$, the complete behaviour of each relevant variable influencing the responses is defined in global terms. The global optimizing results are presented in Table $3 \mathrm{~B}$ and summarized below:

- For the HAE system: the optimal global conditions were at $13.74 \pm 1.91 \mathrm{~min}, \quad 35.64 \pm 7.98{ }^{\circ} \mathrm{C}$, and $100.00 \pm 1.36 \%$ of ethanol, producing $5.78 \pm 0.12 \mathrm{mg} \mathrm{C} / \mathrm{g} \mathrm{R}\left(Y_{1}\right), 4.03 \pm 0.22 \mathrm{mg} \mathrm{C} /$ $\mathrm{g} \mathrm{P} \mathrm{dw}\left(Y_{2}\right)$, and $0.56 \pm 0.02 \mathrm{~g} \mathrm{R} / \mathrm{g} \mathrm{P} \mathrm{dw}\left(Y_{2} / Y_{1}\right)$.
- For the UAE system: the optimal global conditions were at $21.34 \pm 0.55 \mathrm{~min}, 310.58 \pm 25.89 \mathrm{~W}$, and $100.00 \pm 1.36 \%$ of ethanol, producing $9.01 \pm 0.76 \mathrm{mg} \mathrm{C} / \mathrm{g} \mathrm{R}\left(Y_{1}\right), 4.32 \pm 0.14 \mathrm{mg} \mathrm{C} /$ $\mathrm{g} \mathrm{P} \mathrm{dw}\left(Y_{2}\right)$, and $0.51 \pm 0.21 \mathrm{~g} \mathrm{R} / \mathrm{g} \mathrm{P} \mathrm{dw}\left(Y_{2} / Y_{1}\right)$.

- For the MAE system: the optimal global conditions were at $5.00 \pm 0.30 \mathrm{~min}, \quad 62.41 \pm 0.57^{\circ} \mathrm{C}$, and $100.00 \pm 9.00 \%$ of ethanol, producing $7.43 \pm 0.78 \mathrm{mg} \mathrm{C} / \mathrm{g} \mathrm{R}\left(Y_{1}\right), 4.11 \pm 0.37 \mathrm{mg} \mathrm{C} /$ $\mathrm{g} \mathrm{P} \mathrm{dw}\left(Y_{2}\right)$, and $0.76 \pm 0.04 \mathrm{~g} \mathrm{R} / \mathrm{g} \mathrm{P} \mathrm{dw}\left(Y_{2} / Y_{1}\right)$.

For all techniques, the conditions that led to the optimal values were experimentally tested in order to ensure the accuracy of the presented results. Consequently, for the response $Y_{1}$, the UAE technique produced the best results, as the increase of $t$ and $S$ led to a residue with greater purity in cyanidin 3-rutinoside. Regarding the response $Y_{2}$, the MAE produced the higher values, but the increase of the $t$ and $T$ variables led to the degradation of the anthocyanin compound. The UAE gives rise to
HAE

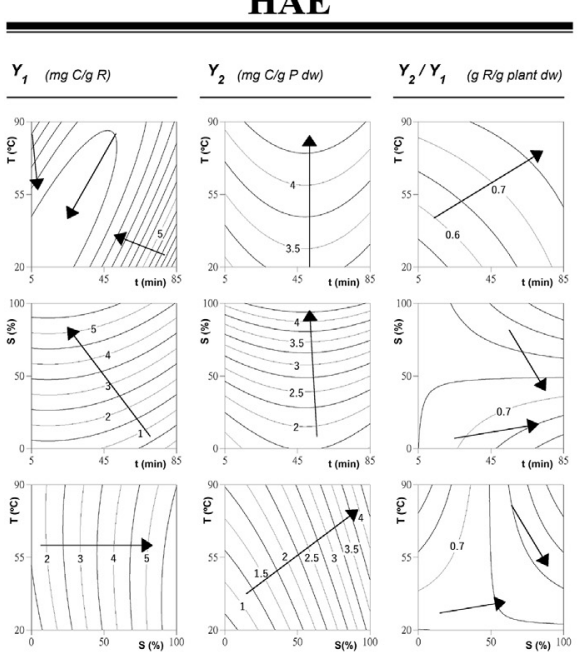

UAE

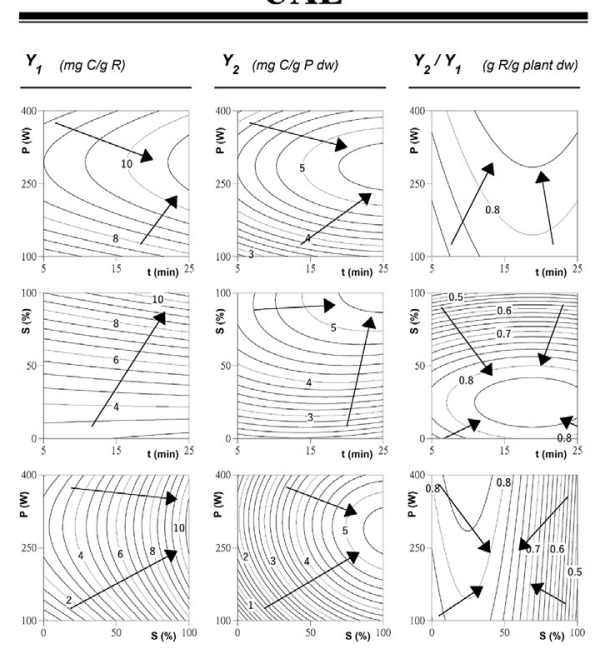

MAE

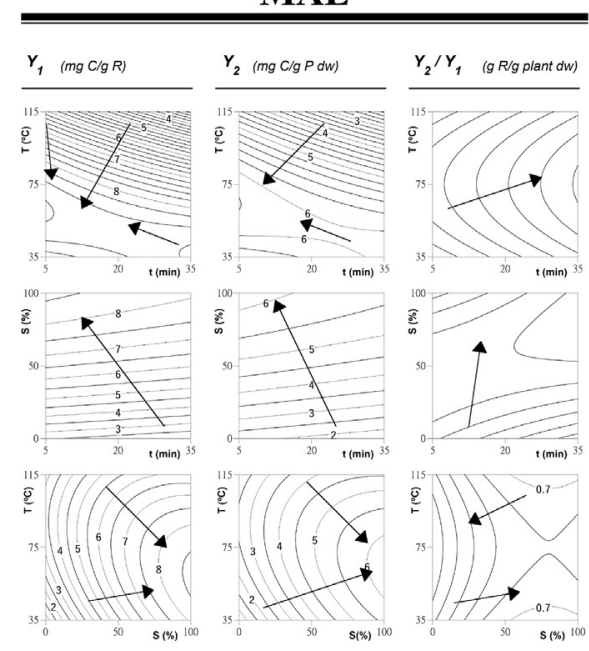

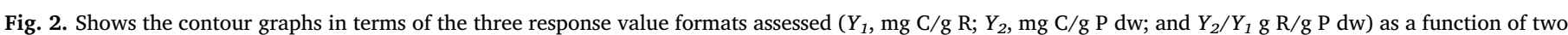

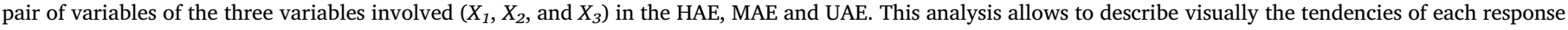

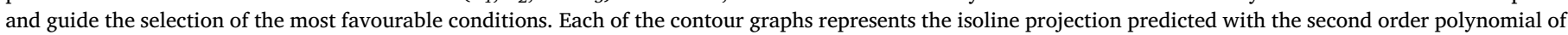

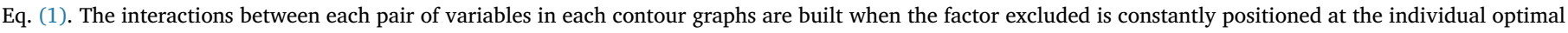
values of the others (Table $3 \mathrm{~A}$ ). The statistical design and experimental results are described in Table 1 . Estimated parametric values are shown in Table 2. 


\section{A: Illustration of the interaction between variables}

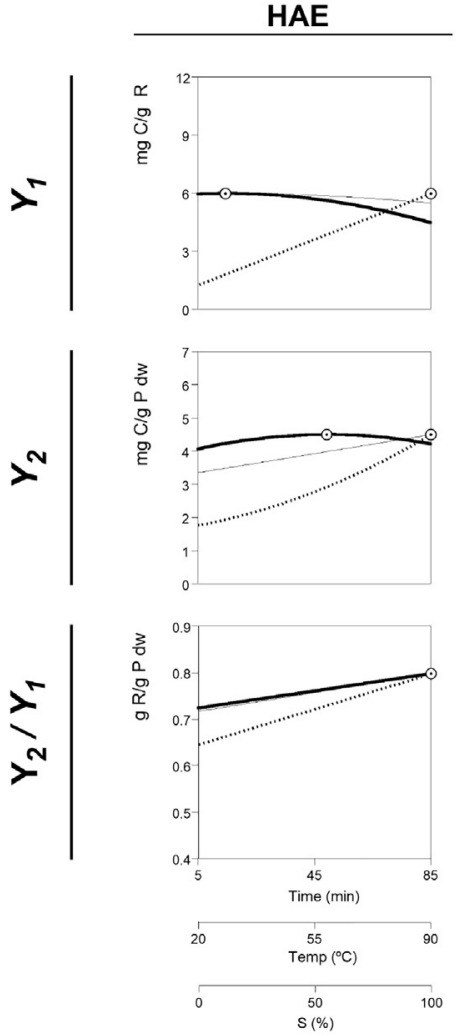

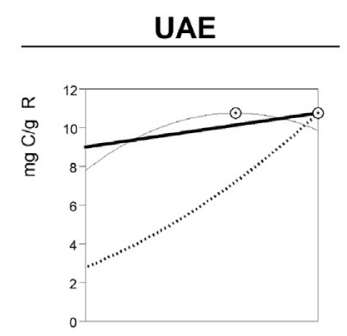
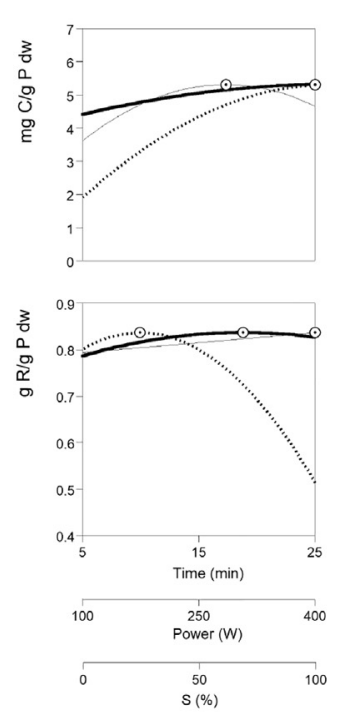

( $\min )$
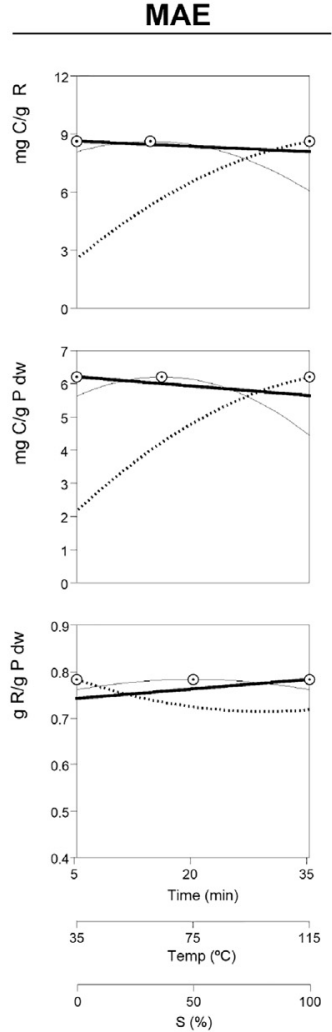

S $(\%)$
Fig. 3. Summary of the effects of each of the variables assessed for HAE, UAE and MAE systems. Part A: Shows the individual responses as a function of all the variables assessed. The variables in each graph were positioned at the individual optimal values of the others (Table 3 ). The points (○) illustrates the position of the optimum value. Lines and dots are generated by the theoretical second order polynomial models derived from Eq. (1). Part B: Shows the dose response of $S / L$ at the global optimal values of the other three variables (Table 3B). Experimental results are represented by dots $(0$, meanwhile lines are the predicted results described by Eq. (2).

\section{B: Solid-to-liquid ratio patterns}
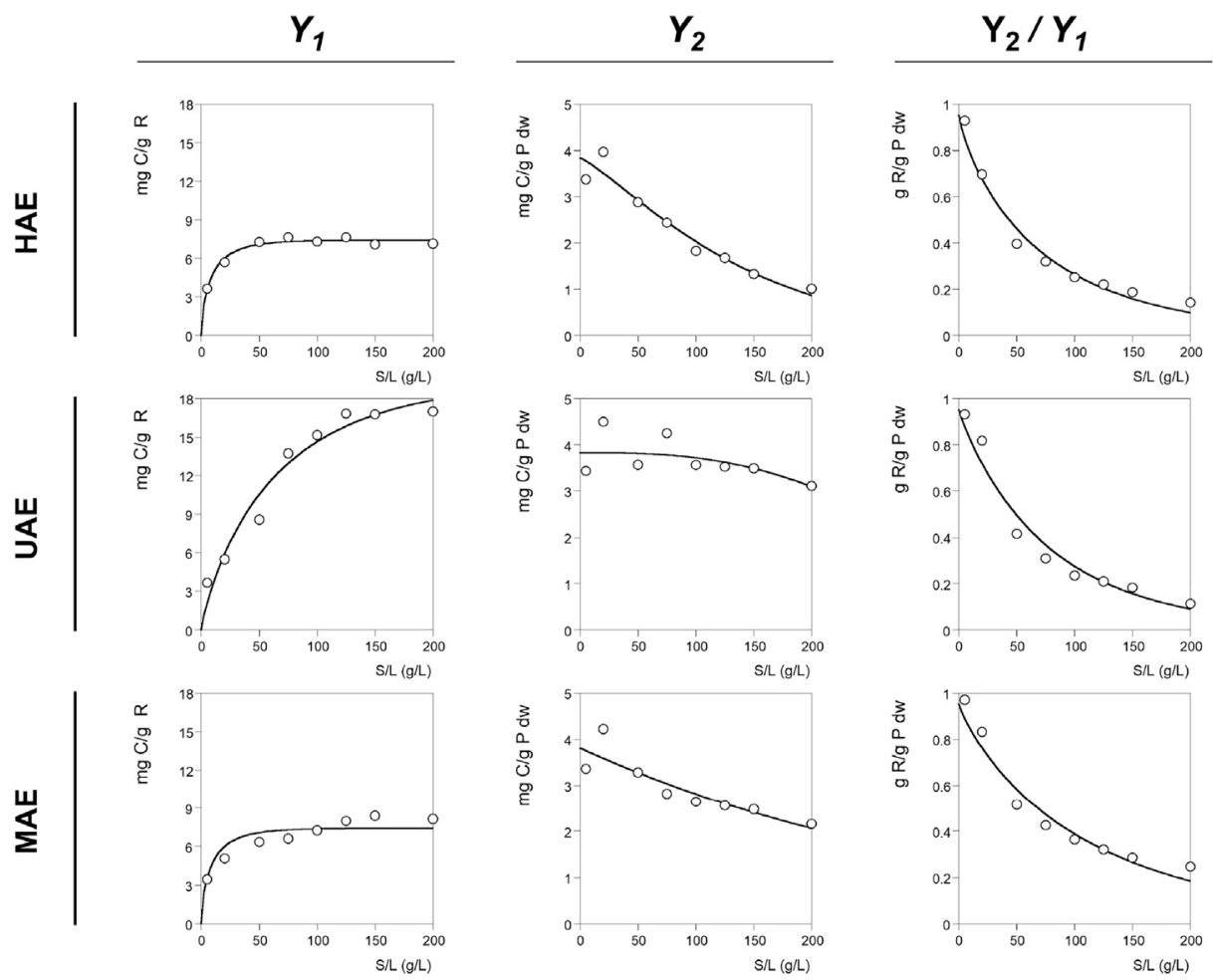
lower $Y_{2}$ values, but the extraction was favoured if longer $t$ and $S$ were used. The HAE extraction system ensures a significant yield value as the variables $S$ and $T$ increases, but when the variable $t$ increases the anthocyanin content decrease. However, the conditions optimized in global terms, the value of the variable $S$ that maximized the cyanidin 3rutinoside extraction is always $100 \%$.

In conclusion, UAE is the best extraction technique, closely followed by MAE, and HAE, which showed to be less effective solutions. These results prove that alternative solid-liquid extraction methods (UAE and MAE) are more suitable than the conventional HAE for the extraction of cyanidin 3-rutinoside from fig peel.

\subsection{Dose-response analysis of the solid-to-liquid effect at the optimum conditions}

As already described in the bibliography, the ideal solid-to-liquid ratio should be the one that allows the solvent to properly penetrate into the structure of the solid matrix (Pinela et al., 2017), but also the one that allows the solvent to dissolve the target compounds (Albuquerque et al., 2016). Therefore, a study aiming to evaluate the $S$ / $L$ effect was conducted at the global optimal conditions predicted by the polynomial models obtained for HAE, UAE, and MAE techniques.

Primary tests were performed to find the limit value of $S / L$. The results showed that over $200 \mathrm{~g} / \mathrm{L}$ the reaction system could not be homogenized properly, thus the dose-response analysis process was designed to analyse the $S / L$ from 5 to $200 \mathrm{~g} / \mathrm{L}$.

The dose-response results to $S / L$ effects of the three response value formats $\left(Y_{1}, Y_{2}\right.$, and $\left.Y_{2} / Y_{1}\right)$ and for the three assessed extraction techniques were evaluated by fitting the Eq. (2) (increasing or decreasing form) to the experimental responses. The obtained parametric values are presented in Table A2 (supplementary material). The effects caused by the $S / L$ on the response value formats are graphically shown in Fig. 3B for the three studied techniques. Fig. 3B shows the experimental results (points $\bigcirc$ and their respective predictions made by the mathematical model of Eq. (2) (lines). In general, a non-linear effect can be observed for all responses as the $S / L$ dose-response increases, causing a saturation-increasing effect $(\uparrow)$ for the $Y_{1}(\mathrm{mg} \mathrm{C} / \mathrm{g} \mathrm{R})$ value format and saturation-decreasing effects $(\downarrow)$ for $Y_{2}(\mathrm{mg} \mathrm{C} / \mathrm{g} \mathrm{P} \mathrm{dw})$ and $Y_{2} / Y_{1}(\mathrm{~g} \mathrm{R} / \mathrm{g} \mathrm{P} \mathrm{dw})$ value formats. The analysis of the results can be interpreted by means of the two main parameters $K$ and $m_{n}$ (at $50 \%$ or $99 \%$ of the response). The parameter $K$ shows the maximum extraction value that can be obtained as a function of the $S / L$ dose-response. Thus, the lower the $m_{n}$ values are, the higher are the reached extraction levels at a shorter dose-response value, which would limit the possibility of reducing the amount of needed solvent, for industrial purposes. Given these considerations, both values are important to understand the trends of the $S / L$ dose-response effect.

In a more detailed analysis, the following aspects can be observed:

- For $Y_{1}$ values, response that gives the purity in $\mathrm{C}$ in the extracted residue: a saturation-increasing dose-response pattern was observed, which means that $Y_{1}$ initially increases as the $S / L$ increases, but when a certain $S / L$ level is reached, the anthocyanin purity remains constant. For HAE, the response rises until $S / L$ reaches values close to $43.58 \pm 0.11 \mathrm{~g} / \mathrm{L}$ (parametric value $m_{99 \%}$ from Eq. (2), Table A2), allowing a concentration of $7.41 \pm 0.59 \mathrm{mg} \mathrm{C} / \mathrm{g} \mathrm{R}$ (parametric value $K$ from Eq. (2), Table A2) that remains constant at high $S / L$ values. For UAE, the $m_{99 \%}$ value was $302.48 \pm 3.48 \mathrm{~g} / \mathrm{L}$, with a $K$ value of $19.40 \pm 0.78 \mathrm{mg} \mathrm{C} / \mathrm{g} \mathrm{R}$, and for MAE, $53.26 \pm 8.91 \mathrm{~g} / \mathrm{L}$ were obtained for $m_{99 \%}$, with a $K$ of $9.71 \pm 1.38 \mathrm{mg} \mathrm{C} / \mathrm{g} \mathrm{R}$. In the performed HAE and MAE, the increased levels of anthocyanin purity achieved by increasing the $S / L$ were not as pronounced as those observed with UAE, fact that may be related to instrumental limitations.

- For $Y_{2}$ values, the response that reflects the C content in the peels: a saturation-decreasing dose-response pattern was observed, which means that $Y_{2}$ initially decreases to zero as $S / L$ increase. For HAE, $\mathrm{UAE}$, and MAE the obtained $m_{50 \%}$ values were $107.39 \pm 9.67$, $302.46 \pm 27.22$, and $225.07 \pm 2.25 \mathrm{~g} / \mathrm{L}$, respectively, presenting $K$ values of $\sim 3.8 \mathrm{mg} \mathrm{C} / \mathrm{g} \mathrm{P} \mathrm{dw}$ for the three tested techniques. These results may probably reflect the total available anthocyanin content in the fig peels, once a maximum concentration was achieved for all the tested extraction methods. Besides, when the $S$ / $L$ increased, a saturation of the solvent was observed, with a decrease of cyanidin 3-rutinoside levels. However, for the modern extraction techniques (UAE and MAE) this decreasing effect is less noted comparatively with the conventional extraction method (HAE). In fact, for UAE and MAE the $S / L$ effect remains almost constant until $\sim 120 \mathrm{~g} / \mathrm{L}$.

- For $Y_{2} / Y_{1}$ values, response that represents the extraction yield of the residue: a saturation-decreasing dose-response pattern was found, which means that $Y_{2}$ initially decreases as $S / L$ increases. For HAE, $\mathrm{UAE}$, and MAE the obtained $m_{50 \%}$ values were $47.32 \pm 1.89$, $53.32 \pm 0.53$, and $74.41 \pm 1.49 \mathrm{~g} / \mathrm{L}$, respectively, with a maximum residue levels of $\sim 0.95 \mathrm{~g} \mathrm{R} / \mathrm{g} \mathrm{P} \mathrm{dw}(K)$, for all the assessed techniques.

Given the widespread interest for anthocyanins, there has been an effort to modernize the extraction protocols, reducing the amount of organic solvents (ecological point of view) and improving the extraction yield (economic point of view) (Jiménez et al., 2018). The lack of optimization approaches, specifically in what concerns anthocyanins extraction contributed to detract the use of these natural solutions in food industry. The study concludes that UAE and MAE, reduce both economic and ecological impacts in comparison with the typically HAE process, in the extraction of cyanidin 3-rutinoside from fig peel in an industrial level (Sicaire et al., 2016).

\subsection{Comparison with other studies involving the extraction of anthocyanins}

To recover anthocyanins from Ficus carica L. infructescences peel to be used as natural food colorant, the optimization of the extraction process is one of the crucial stages towards the industrial implementation. Nevertheless, along with the scarcity of studies on the evaluation of anthocyanin content in F. carica (entire infructescence, pulp, or peel), to the best of our knowledge none of these studies has previously optimized their extraction from these matrices, which hinders results comparison for this particular matrix. Consequently, the reported total anthocyanin values in the fig peel will be compared with bibliographic results in which the entire infructescence was used, as well as with those that have been reported as the major natural sources of anthocyanins (Khadhraoui et al., 2018).

Previous studies have shown that figs contain greater anthocyanin levels than other atypical natural sources (Harzallah et al., 2016; Vallejo et al., 2012). In a recent study conducted by Wojdyło, Nowicka, Carbonell-Barrachina, and Hernández (2016), dealing with the assess of different fig varieties, it was possible to recover 0.01 to $1.2 \mathrm{mg}$ of anthocyanins per $g$ of entire infructescence $d w$, using UAE with methanol as the extraction solvent. These values are lower than those obtained in this study for fig peel at the optimal conditions $(\sim 3.8 \mathrm{mg} / \mathrm{g} \mathrm{P} \mathrm{dw})$. The higher concentration obtained with the fig peel could be partly attributed to the performed optimization procedure, which led to an increased extraction efficiency, and thus anthocyanin yield, when compared with results reported for the entire infructescence (Wojdyło et al., 2016). Moreover, further differences could be explained by the use of different extraction solvents (water-ethanol mixtures vs. methanol). It is a fact that methanol presents a high extraction power, especially for polar molecules such as phenolic compounds. Nevertheless, its use for the extraction of anthocyanin compounds seems to be unrealistic. On the other hand, the hydroalcoholic mixture water-ethanol can be considered a bio-solvent alternative for food industry, if properly removed, leading to higher anthocyanin recovery (Bosiljkov et al., 2017). 
However, the differences found between anthocyanin levels in the entire infructescence and in the peel could by mainly explained by the fact that these compounds tend to be accumulated in the outer parts of the infructescence, such as peels, in the maturity stages chosen for harvest. This fact is well known and has been investigated with other bio-residues rich in anthocyanins, such as mango and sugarcane peels, which present $\sim 0.1 \mathrm{mg} / \mathrm{g} \mathrm{P} \mathrm{dw}$ (Lopes et al., 2016; Zhao et al., 2018). Even so, the anthocyanin concentration detected in these matrices are far below those found in the fig peels assessed in the present study. Given the fact that in almost all industrial processes involving fig infructescence's they are used in very mature stages, the discarded parts of the fig, including the peels, can become relevant by-products if recovered for extraction of anthocyanins, compounds with natural colouring properties that could be applied as natural additives.

Generally, the most common rich sources of anthocyanins are those derived from Oryza sativa L. (var. Glutinosa), presenting $42 \mathrm{mg} / \mathrm{g} \mathrm{dw}$ (Chen, McClung, \& Bergman, 2017), Phaseolus vulgaris L. (common beans), with $32 \mathrm{mg} / \mathrm{g} \mathrm{dw}$ (Mojica, Berhow, \& Gonzalez de Mejia, 2017), and Rubus fruticosus L. fruits (blackberries), with $17.10 \mathrm{mg} / \mathrm{g}$ dw (Elisia, $\mathrm{Hu}$, Popovich, \& Kitts, 2006). Although these values are considerably higher than those presented by fig peels, these sources have an already recognized commercial value for other purposes, contrarily to fig peels. Considering that other matrices, such as eggplant peel $(0.6 \mathrm{mg} / \mathrm{g} \mathrm{dw})$ (Todaro et al., 2009) or grape bark ( $1 \mathrm{mg} / \mathrm{g} \mathrm{dw}$ ) (Chen et al., 2015), are currently used as common sources of anthocyanins, even presenting a lower concentration than the one found in fig peels, this matrix arises as a promising by-product to be explored for colorant industrial application purposes.

\section{Conclusions}

Due to the great interest of using natural pigments, such as anthocyanins, in food, pharmaceutical, and cosmetic industries, in the present work different solid-liquid extraction methods were studied and optimized by RSM. The selected techniques were HAE, UAE, and MAE, using three independent variables $(t, T$, and $S$ for HAE and MAE, and $t$, $P$, and $S$ for UAE) to maximize the defined responses: $\mathrm{mg} \mathrm{C} / \mathrm{g} \mathrm{R}\left(Y_{1}\right) ; \mathrm{mg}$ $\mathrm{C} / \mathrm{g} \mathrm{P}$ dw $\left(Y_{2}\right)$; and $\mathrm{g} \mathrm{R} / \mathrm{g} \mathrm{P} \mathrm{dw}\left(Y_{2} / Y_{1}\right)$. The UAE was the most effective method of this study, capable of producing $3.8 \mathrm{mg} \mathrm{C} / \mathrm{g} \mathrm{P} \mathrm{dw}$ and $0.95 \mathrm{~g}$ $\mathrm{R} / \mathrm{g} \mathrm{P} \mathrm{dw}$, with an anthocyanin content of $19.4 \mathrm{mg} \mathrm{C} / \mathrm{g} \mathrm{R}$. These values were obtained at the optimum conditions $(21.34 \pm 0.55 \mathrm{~min}$, $310.58 \pm 25.89 \mathrm{~W}, 100 \%$ ethanol, and $183.01 \pm 22.82 \mathrm{~g} / \mathrm{L})$. The HAE and MAE techniques revealed similar performances, but slightly lower than the one obtained for UAE. When $S / L$ variable was tested, a significant effect was noticed with UAE, resulting in an extract with an increased purity as the $S / L$ increased.

The analysis presented provides important data that allows the comparison between different extraction methods, in terms of efficiency, and consequent related decision making. In an industrial level, these methodologies reduce costs related to energy, solvent consumption, equipment investment, etc. Achieving the optimal conditions and maximum the responses is an important step to guide the choice of a suitable and sustainable process.

\section{Acknowledgements}

The authors are grateful to the Foundation for Science and Technology (FCT, Portugal) and FEDER under Programme PT2020 for financial support to CIMO (UID/AGR/00690/2013); to FCT for L. Barros research contract and C. Pereira grant (SFRH/BPD/122650/ 2016) under the Programa Operacional Capital Humano (POCH) supported by the European Social Fund and National Funds of MCTES (Ministério da Ciência, Tecnologia, e Ensino Superior); to FEDERInterreg España-Portugal programme for financial support through the project 0377_Iberphenol_6_E.; to European Structural and Investment Funds (FEEI) through the Regional Operational Program North 2020, within the scope of Mobilizador project Norte-01-0247-FEDER-024479: ValorNatural ${ }^{\circledR}$ and Project NORTE-01-0145-FEDER-023289: DeCodE. This work was also financially supported by: Project POCI-01-0145FEDER-006984 - Associate Laboratory LSRE-LCM funded by FEDER through COMPETE2020 - Programa Operacional Competitividade e Internacionalização (POCI) - and by national funds through FCT Fundação para a Ciência e a Tecnologia. To Xunta de Galicia for financial support to M.A. Prieto grant.

\section{Abbreviations}

\section{General abbreviations}

HPLC-DAD-ESI/MS High-performance liquid chromatography coupled to photodiode array detector and mass spectrometer

Eq. or Eqs. Equation or equations

C Cyanidin 3-rutinoside

P Fig peel

$\mathrm{R} \quad$ Extracted dried weight residue

dw Dry weight

RSM Response surface methodology

CCCD Circumscribed central composite design

MAE Microwave assisted extraction

UAE Ultrasound assisted extraction

HAE Heat assisted extractionResponse surface methodology exVariables perimental design and model equations:

$t \quad$ Time or $X_{1}(\min )$

$T \quad$ Temperature or $X_{2}\left({ }^{\circ} \mathrm{C}\right)$

$S \quad$ Solvent proportion or $X_{2}(\% \mathrm{v} / \mathrm{v}$ of ethanol in hydroalcoholic mixtures)

$P \quad$ Ultrasonic power or $X_{2}(\mathrm{~W})$

$S / L \quad$ Solid-to-liquid ratio or $X_{2}(\mathrm{~g} / \mathrm{L})$

Responses

$Y_{1} \quad \mathrm{mg}$ of cyanidin 3-rutinoside obtained in the extracted dried weight residue ( $\mathrm{R} ; \mathrm{mg} \mathrm{C} / \mathrm{g} \mathrm{R})$

$\mathrm{Y}_{2} \quad \mathrm{mg}$ of cyanidin 3-rutinoside per $\mathrm{g}$ of peel dry matter $(\mathrm{mg} \mathrm{C} / \mathrm{g}$ $\mathrm{P} \mathrm{dw}$ )

$Y_{2} / Y_{1} \quad$ obtained by dividing the responses $Y_{2}$ and $Y_{1}$, which provides information regarding the extraction yield of the dried weight residue ( $\mathrm{g}$ of $\mathrm{R} / \mathrm{g}$ P dw)Equation

Eq. (1) Second-order polynomial equation

$Y \quad$ Dependent variable to be modelled

$X_{i}$ and $X_{j}$ Independent variables to be assessed

$b_{0} \quad$ Constant coefficient.

$b_{i} \quad$ Coefficients of linear effect.

$b_{i j} \quad$ Coefficients of interaction effect

$b_{i i} \quad$ Coefficient of quadratic effect

$n \quad$ Number of variables

Eqs. (3) to (11) Second-order polynomial equation derived from Eq. (1) that describe all response formats for all techniques testedDose-response description of the solid-to-liquid ratio effect

W Weibull equation

$\mathrm{W}(\uparrow) \quad$ Increasing Weibull equation

$W(\downarrow) \quad$ Decreasing Weibull equation

Eq. (2) Number of the Weibull equation in its increasing and decreasing form

$K \quad$ Maximum extraction value. Units would depend in the response format $\left(Y_{1}, Y_{2}\right.$, and $\left.Y_{2} / Y_{1}\right)$ assessed (i.e., if $Y_{2}$ the units would be in $\mathrm{mg} \mathrm{C} / \mathrm{g} \mathrm{P} \mathrm{dw}$ )

$a$ Shape parameter related to the maximum slope of the response

$n \quad$ Any desired level between 0 and $100 \%$ of the response $\left(Y_{1}\right.$, $Y_{2}$, and $Y_{2} / Y_{1}$ ) 
$m_{n} \quad$ The $S / L$ parametric value for the selected $n$ response level $\left(m_{10}, m_{25}, m_{75}, m_{95}\right.$, etc.)Statistical evaluation

ns Non-significant coefficient

Obs Number of observations

$R^{2} \quad$ Coefficient of determination

$R^{2} a d j \quad$ Adjusted determination coefficient

\section{Appendix A. Supplementary data}

Supplementary data to this article can be found online at https:// doi.org/10.1016/j.foodres.2018.07.016.

\section{References}

Albuquerque, B. R., Prieto, M. A., Barreiro, M. F., Rodrigues, A., Curran, T. P., Barros, L., \& Ferreira, I. C. F. R. (2016). Catechin-based extract optimization obtained from Arbutus unedo L. fruits using maceration/microwave/ultrasound extraction techniques. Industrial Crops and Products, 95, 404-415.

Azmir, J., Zaidul, I. S. M., Rahman, M. M., Sharif, K. M., Mohamed, A., Sahena, F., ... M, A. K. (2013). Techniques for extraction of bioactive compounds from plant materials: A review. Journal of Food Engineering, 117(4), 426-436.

Bezerra, M. A., Santelli, R. E., Oliveira, E. P., Villar, L. S., Escaleira, E. A., \& Escaleira, L. A. (2008). Response surface methodology (RSM) as a tool for optimization in analytical chemistry. Talanta, 76(5), 965-977.

Bonfigli, M., Godoy, E., Reinheimer, M. A., \& Scenna, N. J. (2017). Comparison between conventional and ultrasound-assisted techniques for extraction of anthocyanins from grape pomace. Experimental results and mathematical modeling. Journal of Food Engineering, 207, 56-72.

Bosiljkov, T., Dujmić, F., Cvjetko Bubalo, M., Hribar, J., Vidrih, R., Brnčić, M., ... Jokić, S. (2017). Natural deep eutectic solvents and ultrasound-assisted extraction: Green approaches for extraction of wine lees anthocyanins. Food and Bioproducts Processing, 102, 195-203.

Caleja, C., Barros, L., Prieto, M. A., Barreiro, F. M. F., Oliveira, M. B. P., \& Ferreira, I. C. F. R. (2017). Extraction of rosmarinic acid from Melissa officinalis L. by heat-, microwave- and ultrasound-assisted extraction techniques: A comparative study through response surface analysis. Separation and Purification Technology, 186, 297-308.

Chan, C. H., Yusoff, R., \& Ngoh, G. C. (2013). Modeling and prediction of extraction profile for microwave-assisted extraction based on absorbed microwave energy. Food Chemistry, 140(1-2), 147-153.

Chemat, F., Rombaut, N., Meullemiestre, A., Turk, M., Perino, S., Fabiano-Tixier, A. S., \& Abert-Vian, M. (2017). Review of green food processing techniques. Preservation, transformation, and extraction. Innovative Food Science and Emerging Technologies, 41, 357-377.

Chemat, F., Rombaut, N., Sicaire, A. G., Meullemiestre, A., Fabiano-Tixier, A. S., \& AbertVian, M. (2017). Ultrasound assisted extraction of food and natural products. Mechanisms, techniques, combinations, protocols and applications. A review. Ultrasonics Sonochemistry, 34, 540-560.

Chen, M. H., McClung, A. M., \& Bergman, C. J. (2017). Phenolic content, anthocyanins and antiradical capacity of diverse purple bran rice genotypes as compared to other bran colors. Journal of Cereal Science, 77, 110-119.

Chen, S., Zhang, F., Ning, J., Liu, X., Zhang, Z., \& Yang, S. (2015). Predicting the anthocyanin content of wine grapes by NIR hyperspectral imaging. Food Chemistry, 172, 788-793.

Dai, J., \& Mumper, R. J. (2010). Plant phenolics: Extraction, analysis and their antioxidant and anticancer properties. Molecules, 15(10), 7313-7352.

Elisia, I., Hu, C., Popovich, D. G., \& Kitts, D. D. (2006). Antioxidant assessment of an anthocyanin-enriched blackberry extract. Food Chemistry, 101(3), 1052-1058.

Estupiñan, D. C., Schwartz, S. J., \& Garzón, G. A. (2011). Antioxidant activity, Total Phenolics content, anthocyanin, and color stability of isotonic model beverages colored with Andes berry (Rubus glaucus Benth) anthocyanin powder. Journal of Food Science, 76(1), S26-S34.

Fattore, M., Montesano, D., Pagano, E., Teta, R., Borrelli, F., Mangoni, A., ... Albrizio, S. (2016). Carotenoid and flavonoid profile and antioxidant activity in "Pomodorino Vesuviano" tomatoes. Journal of Food Composition and Analysis, 53(1238), 61-68.

Ferreira, S. L. C., Bruns, R. E., Ferreira, H. S., Matos, G. D., David, J. M., Brandão, G. C., .. dos Santos, L, W. N. (2007). Box-Behnken design: An alternative for the optimization of analytical methods. Analytica Chimica Acta, 597(2), 179-186.

García-Moreno, P. J., Batista, I., Pires, C., Bandarra, N. M., Espejo-Carpio, F. J., Guadix, A., \& Guadix, E. M. (2014). Antioxidant activity of protein hydrolysates obtained from discarded Mediterranean fish species. Food Research International, 65(PC), 469-476.

Gonçalves, G. A., Soares, A. A., Correa, R. C. G., Barros, L., Haminiuk, C. W. I., Peralta, R. M., ... Bracht, A. (2017). Merlot grape pomace hydroalcoholic extract improves the oxidative and inflammatory states of rats with adjuvant-induced arthritis. Journal of Functional Foods, 33, 408-418.

Gowd, V., Jia, Z., \& Chen, W. (2017). Anthocyanins as promising molecules and dietary bioactive components against diabetes - A review of recent advances. Trends in Food Science and Technology, 68, 1-13.

Harzallah, A., Bhouri, A. M., Amri, Z., Soltana, H., \& Hammami, M. (2016). Phytochemical content and antioxidant activity of different fruit parts juices of three figs (Ficus carica L.) varieties grown in Tunisia. Industrial Crops and Products, 83,
$255-267$.

Jacotet-Navarro, M., Rombaut, N., Deslis, S., Fabiano-Tixier, A.-S., Pierre, F.-X., Bily, A., \& Chemat, F. (2016). Towards a "dry" bio-refinery without solvents or added water using microwaves and ultrasound for total valorization of fruit and vegetable byproducts. Green Chemistry, 18(10), 3106-3115.

Jiménez, L. C., Caleja, C., Prieto, M. A., Barreiro, M. F., Barros, L., \& Ferreira, I. C. F. R. (2018). Optimization and comparison of heat and ultrasound assisted extraction techniques to obtain anthocyanin compounds from Arbutus unedo L. fruits. Food Chemistry, 264, 81-91.

Kalil, S., \& Maugeri, F. (2000). Response surface analysis and simulation as a tool for bioprocess design and optimization. Process Biochemistry, 35, 539-550.

Khadhraoui, B., Turk, M., Fabiano-Tixier, A. S., Petitcolas, E., Robinet, P., Imbert, R., \& Chemat, F. (2018). Histo-cytochemistry and scanning electron microscopy for studying spatial and temporal extraction of metabolites induced by ultrasound. Towards chain detexturation mechanism. Ultrasonics Sonochemistry, 42(November 2017), 482-492.

Lopes, M. M. A., Silva, E. O., Canuto, K. M., Silva, L. M. A., Gallão, M. I., Urban, L., ... Miranda, M. R. A. (2016). Low fluence pulsed light enhanced phytochemical content and antioxidant potential of "Tommy Atkins" mango peel and pulp. Innovative Food Science and Emerging Technologies, 33, 216-224.

Meullemiestre, A., Breil, C., Abert-Vian, M., \& Chemat, F. (2016). Microwave, ultrasound, thermal treatments, and bead milling as intensification techniques for extraction of lipids from oleaginous Yarrowia lipolytica yeast for a biojetfuel application. Bioresource Technology, 211, 190-199.

Mojica, L., Berhow, M., \& Gonzalez De Mejia, E. (2017). Black bean anthocyanin-rich extracts as food colorants: Physicochemical stability and antidiabetes potential. Food Chemistry, 229, 628-639.

Montesano, D., Fallarino, F., Cossignani, L., Bosi, A., Simonetti, M. S., Puccetti, P., \& Damiani, P. (2008). Innovative extraction procedure for obtaining high pure lycopene from tomato. European Food Research and Technology, 226(3), 327-335.

Murado, M. A., \& Prieto, M. A. (2013). Dose-response analysis in the joint action of two effectors. A new approach to simulation, identification and modelling of some basic interactions. PLoS One, 8(4), e61391.

Ongkowijoyo, P., Luna-Vital, D. A., \& Gonzalez De Mejia, E. (2018). Extraction techniques and analysis of anthocyanins from food sources by mass spectrometry: An update. Food Chemistry, 250(July 2017), 113-126.

Palassarou, M., Melliou, E., Liouni, M., Michaelakis, A., Balayiannis, G., \& Magiatis, P. (2017). Volatile profile of Greek dried white figs (Ficus carica L.) and investigation of the role of $\beta$-damascenone in aroma formation in fig liquors. Journal of the Science of Food and Agriculture, 97(15), 5254-5270.

Pinela, J., Prieto, M. A., Barreiro, M. F., Carvalho, A. M., Oliveira, M. B. P. P., Curran, T. P., \& Ferreira, I. C. F. R. (2017). Valorisation of tomato wastes for development of nutrient-rich antioxidant ingredients: A sustainable approach towards the needs of the today's society. Innovative Food Science and Emerging Technologies, 41, 160-171.

Prieto, M. A., Curran, T. P., Gowen, A., \& Vázquez, J. A. (2015). An efficient methodology for quantification of synergy and antagonism in single electron transfer antioxidant assays. Food Research International, 67, 284-298.

Prieto, M. A., \& Vázquez, J. A. (2014). In vitro determination of the lipophilic and hydrophilic antioxidant capacity of unroasted coffee bean extracts and their synergistic and antagonistic effects. Food Research International, 62(10), 1183-1196.

Ranic, M., Nikolic, M., Pavlovic, M., Buntic, A., Siler-Marinkovic, S., \& DimitrijevicBrankovic, S. (2014). Optimization of microwave-assisted extraction of natural antioxidants from spent espresso coffee grounds by response surface methodology. Journal of Cleaner Production, 80, 69-79.

Rodriguez-Amaya, D. B. (2016). Natural food pigments and colorants. Current opinion in food science. Vol. 7. Current opinion in food science (pp. 20-26). Elsevier Ltd.

Rustioni, L., Di Meo, F., Guillaume, M., Failla, O., \& Trouillas, P. (2013). Tuning color variation in grape anthocyanins at the molecular scale. Food Chemistry, 141(4), 4349-4357.

Salem, N., Msaada, K., Elkahoui, S., Mangano, G., Azaeiz, S., Ben Slimen, I., ... Marzouk, B. (2014). Evaluation of antibacterial, antifungal, and antioxidant activities of safflower natural dyes during flowering. BioMed Research International, 2014, 1-10.

Sang, J. J., Sang, J. J., Ma, Q., Hou, X.f., \& Li, C.q. (2017). Extraction optimization and identification of anthocyanins from Nitraria tangutorun Bobr. Seed meal and establishment of a green analytical method of anthocyanins. Food Chemistry, 218, 386-395.

Sicaire, A. G., Vian, M. A., Fine, F., Carré, P., Tostain, S., \& Chemat, F. (2016). Ultrasound induced green solvent extraction of oil from oleaginous seeds. Ultrasonics Sonochemistry, 31, 319-329.

Todaro, A., Cimino, F., Rapisarda, P., Catalano, A. E., Barbagallo, R. N., \& Spagna, G. (2009). Recovery of anthocyanins from eggplant peel. Food Chemistry, 114(2), 434-439.

Tsatsop, R. K. T., Djiobie, G. T., Kenmogne, B. S., Regonne, K. R., \& Ngassoum, M. B. (2016). Optimization of microwave-assisted extraction of bioactive compounds from Anogeissus Leiocarpus Guill. \& Perr. Stem bark using response surface methodology. International Journal of Scientific \& Technology Research, 5(05), 1-8.

Vallejo, F., Marín, J. G., \& Tomás-Barberán, F. A. (2012). Phenolic compound content of fresh and dried figs (Ficus carica L.). Food Chemistry, 130(3), 485-492.

Vieira, V., Prieto, M. A., Barros, L., Coutinho, J. A. P., Ferreira, O., \& Ferreira, I. C. F. R. (2017). Optimization and comparison of maceration and microwave extraction systems for the production of phenolic compounds from Juglans regia L. for the valorization of walnut leaves. Industrial Crops and Products, 107, 341-352.

Wang, Z., Cui, Y., Vainstein, A., Chen, S., \& Ma, H. (2017). Regulation of fig (Ficus carica L.) fruit color: Metabolomic and Transcriptomic analyses of the flavonoid biosynthetic pathway. Frontiers in Plant Science, 8(November), 1-15.

Wojdyło, A., Nowicka, P., Carbonell-Barrachina, Á. A., \& Hernández, F. (2016). Phenolic 
compounds, antioxidant and antidiabetic activity of different cultivars of Ficus carica L. fruits. Journal of Functional Foods, 25, 421-432.

Zhao, Z., Yan, H., Zheng, R., Khan, M. S., Fu, X., Tao, Z., \& Zhang, Z. (2018).

Anthocyanins characterization and antioxidant activities of sugarcane (Saccharum officinarum L.) rind extracts. Industrial Crops and Products, 113(January), 38-45.

Zhu, Z., He, J., Liu, G., Barba, F. J., Koubaa, M., Ding, L., ... Vorobiev, E. (2016). Recent insights for the green recovery of inulin from plant food materials using non-conventional extraction technologies: A review. Innovative Food Science and Emerging Technologies, 33, 1-9.

Zhu, Z., Wu, Q., Di, X., Li, S., Barba, F. J., Koubaa, M., \& He, J. (2017). Multistage recovery process of seaweed pigments: Investigation of ultrasound assisted extraction and ultra-filtration performances. Food and Bioproducts Processing, 104, 40-47. 